\title{
Chronic Stress Exacerbates Tau Pathology, Neurodegeneration, and Cognitive Performance through a Corticotropin-Releasing Factor Receptor-Dependent Mechanism in a Transgenic Mouse Model of Tauopathy
}

\author{
Jenna C. Carroll, ${ }^{1}$ Michiyo Iba, ${ }^{1}$ Debra A. Bangasser, ${ }^{3}$ Rita J. Valentino, ${ }^{3}$ Michael J. James, ${ }^{1}$ Kurt R. Brunden, ${ }^{1}$ \\ Virginia M.-Y. Lee, ${ }^{1}$ and John Q. Trojanowski ${ }^{1,2}$ \\ ${ }^{1}$ Center for Neurodegenerative Disease Research, Department of Pathology and Laboratory Medicine, School of Medicine and ${ }^{2}$ Institute on Aging,

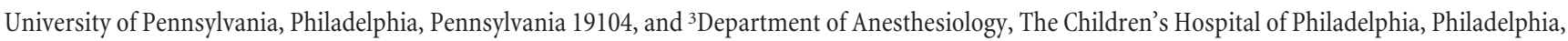 \\ Pennsylvania 19104
}

\begin{abstract}
Because overactivation of the hypothalamic-pituitary-adrenal (HPA) axis occurs in Alzheimer's disease (AD), dysregulation of stress neuromediators may play a mechanistic role in the pathophysiology of AD. However, the effects of stress on tau phosphorylation are poorly understood, and the relationship between corticosterone and corticotropin-releasing factor (CRF) on both $\beta$-amyloid $(\mathrm{A} \beta)$ and tau pathology remain unclear. Therefore, we first established a model of chronic stress, which exacerbates $\mathrm{A} \beta$ accumulation in Tg2576 mice and then extended this stress paradigm to a tau transgenic mouse model with the P301S mutation (PS19) that displays tau hyperphosphorylation, insoluble tau inclusions and neurodegeneration. We show for the first time that both Tg2576 and PS19 mice demonstrate a heightened HPA stress profile in the unstressed state. In Tg2576 mice, 1 month of restraint/isolation (RI) stress increased A $\beta$ levels, suppressed microglial activation, and worsened spatial and fear memory compared with nonstressed mice. In PS19 mice, RI stress promoted tau hyperphosphorylation, insoluble tau aggregation, neurodegeneration, and fear-memory impairments. These effects were not mimicked by chronic corticosterone administration but were prevented by pre-stress administration of a CRF receptor type $1\left(\mathrm{CRF}_{1}\right)$ antagonist. The role for a $\mathrm{CRF}_{1}$-dependent mechanism was further supported by the finding that mice overexpressing CRF had increased hyperphosphorylated tau compared with wild-type littermates. Together, these results implicate HPA dysregulation in AD neuropathogenesis and suggest that prolonged stress may increase $\mathrm{A} \beta$ and tau hyperphosphorylation. These studies also implicate CRF in AD pathophysiology and suggest that pharmacological manipulation of this neuropeptide may be a potential therapeutic strategy for AD.
\end{abstract}

\section{Introduction}

Alzheimer's disease $(\mathrm{AD})$ is an age-related neurodegenerative disorder characterized by memory deficits, neuron loss, $\beta$-amyloid $(\mathrm{A} \beta)$ deposited in amyloid plaques and neurofibrillary tangles composed of hyperphosphorylated tau fibrils. Convergent evidence implicates stress in $\mathrm{AD}$ neuropathology. For example, $\mathrm{AD}$ and stress disorders are characterized by hypothalamic-pituitary-adrenal (HPA) dysfunction (Swaab et al., 2005;

\footnotetext{
Received July 27, 2011; accepted Aug. 12, 2011.

Author contributions: J.C.C., R.J.V., K.R.B., V.M.-Y.L., and J.Q.T. designed research; J.C.C. and M.J.J. performed research; M.I., D.A.B., and R.J.V. contributed unpublished reagents/analytic tools; J.C.C. and R.J.V. analyzed data; J.C.C., R.J.V., K.R.B., V.M.-Y.L., and J.Q.T. wrote the paper.

This work was supported by NIH Grants P01 AG17586 (V.M.-Y.L.) and MH40008 (R.J.V.) and a University of Pennsylvania Comprehensive Neuroscience Center grant (R.J.V. and V.M.-Y.L.). We thank R. Vassar for the generous BACE antibody gift, T. Bale for expert advice on CORT measurements, and K. Siniakowicz for technical assistance.

The authors declare no conflicts of interest.

Correspondence should be addressed to Dr. John Q. Trojanowski, Center for Neurodegenerative Disease Research, Department of Pathology and Laboratory Medicine, University of Pennsylvania, 3600 Spruce Street, Maloney 3rd Floor, Philadelphia, PA 19104. E-mail: trojanow@mail.med.upenn.edu.

DOI:10.1523/JNEUROSCI.3836-11.2011

Copyright $\odot 2011$ the authors $\quad 0270-6474 / 11 / 3114436-14 \$ 15.00 / 0$
}

Holsboer and Ising, 2008; Pervanidou and Chrousos, 2010), whereas psychological stress increases $\mathrm{AD}$ risk (Wilson et al., 2006) and $\mathrm{AD}$ is associated with stress-related disorders (Aznar and Knudsen, 2011).

This notwithstanding, the molecular mechanisms linking stress to $\mathrm{AD}$ pathogenesis remain unknown. With stress, hippocampal glucocorticoid receptor activation increases neuronal metabolism, decreases cell survival and neurogenesis, promotes dendritic atrophy, and causes long-term potentiation and cognition deficits (Sapolsky et al., 1985; McEwen, 1999; Kim and Diamond, 2002; Rothman and Mattson, 2010). Elevated glucocorticoid levels, characteristic of chronic stress, are associated with cognitive symptoms of dementia in elderly and AD subjects (Csernansky et al., 2006; Lee et al., 2008). From these observations, the glucocorticoid hypothesis of brain aging emerged, proposing that chronic stress and/or glucocorticoid exposure promotes hippocampal aging and even $\mathrm{AD}$ pathogenesis (Landfield et al., 2007). Although it has been well established that chronic stress exacerbates $\mathrm{A} \beta$ accumulation and memory deficits in $\mathrm{AD}$ transgenic ( $\mathrm{Tg}$ ) mice (Green et al., 2006; Jeong et al., 2006; Kang et al., 2007; Lee et al., 2009; Huang et al., 2011), the involve- 
ment of a glucocorticoid receptor-dependent pathway remains controversial. Recent studies have implicated corticotropinreleasing factor (CRF) as a more likely causal factor in stressinduced $A \beta$ increases (Kang et al., 2007), although it may also offer protective effects (Bayatti and Behl, 2005). CRF acts via G-protein-coupled receptor type $1\left(\mathrm{CRF}_{1}\right)$ with widespread brain expression to orchestrate the stress response (Bale and Vale, 2004). CRF overproduction is implicated in stress-related psychopathology, such as depression, anxiety, and posttraumatic stress disorder (Hillhouse and Grammatopoulos, 2006; Hauger et al., 2009; Pervanidou and Chrousos, 2010; Stengel and Tache, 2010).

The majority of studies examining stress contributions to $\mathrm{AD}$ pathology have focused on $A \beta$ plaques, whereas less has been reported about stress-related effects on disease-relevant tau pathology. A substantial body of literature demonstrates that tau phosphorylation is induced by various environmental insults, such as cold (Korneyev et al., 1995; Feng et al., 2005), heat (Papasozomenos, 1996), hypoglycemia (Yanagisawa et al., 1999), starvation (Planel et al., 2001), hibernation (Arendt et al., 2003), social isolation (Zhang et al., 2011), and restraint (Yan et al., 2010), which may be $\mathrm{CRF}_{1}$ mediated (Rissman et al., 2007). However, these data were generated almost exclusively in non-Tg rodents. Thus, no studies have addressed $\mathrm{CRF}_{1}$ mediated mechanisms of tau hyperphosphorylation in a diseaserelevant Tg mouse model. Therefore, we sought to establish and validate a chronic stress paradigm using the Tg2576 mouse model in which mutated $\mathrm{A} \beta$ precursor protein found in familial $\mathrm{AD}$ is overexpressed and then investigate the mechanisms behind stress-induced tau pathology using established Tg mouse models that either overexpress mutant tau (PS19) found in familial frontotemporal degeneration or CRF. Our data implicate $\mathrm{CRF}_{1}$ dependent mechanisms in the pathophysiology of AD.

\section{Materials and Methods}

Mouse cohorts. Three separate cohorts of different Tg mice were used in this study: (1) female hemizygous Tg2576 harboring the amyloid precursor protein Swedish $\left(\mathrm{APP}_{\text {swe }}\right)$ mutation and wild-type (WT) mice of the same genetic background (BL6SJL/J) in experiment 1, (2) male hemizygous PS19 harboring P301S mutant human tau (Yoshiyama et al., 2007) and WT mice of the same genetic background $(\mathrm{BL} 6 / \mathrm{C} 3 \mathrm{H})$ in experiments 2 and 3 , and (3) female CRF-overexpressing (CRF-OE) (Stenzel-Poore et al., 1992) and WT mice of the same genetic background (C57BL/6J) in experiment 4. Tg2576 and PS19 mice were housed with same-sex littermates at The University of Pennsylvania School of Medicine, and CRF-OE mice were purchased from The Jackson Laboratories and housed at The Children's Hospital of Philadelphia. All procedures were approved by the University of Pennsylvania Institutional Animal Care and Use Committee. Separate groups of Tg2576 and WT mice $(n=10$ per group) were evaluated at 4 or 14 months of age in experiment 1. PS19 and WT mice ( $n=8$ per group) were evaluated at 6 months of age in experiment 2 or 8 months of age in experiments 3 and 4 . Finally, the third cohort of female WT and CRF-OE mice ( $n=6$ per group) were evaluated at 10 months of age.

In general, mice were evaluated on behavioral tests and then exposed to either drug treatment or chronic stress, or no stress for 1 month. After 1 month of chronic stress and/or treatment, mice were again administered behavioral tests, followed by corticosterone analysis after an acute stress and then killed. At time of death, mice were deeply anesthetized with ketamine/xylazine $(100 \mathrm{mg} / \mathrm{kg}$ ketamine and $10 \mathrm{mg} / \mathrm{kg}$ xylazine) and were perfused with $10 \mathrm{~mm}$ PBS with heparin. Brains were bisected, and one hemibrain was fixed for $24 \mathrm{~h}$ in $10 \%$ Neutral Buffered Formalin for immunohistochemical analysis, whereas the other hemibrain was dissected, weighed, and frozen for biochemical analysis. The adrenal cortex was weighed as bioassay of stress.
Stress paradigms. Mice were exposed to 1 month of no stress (NS), variable stress (VS), or restraint/isolation (RI) stress as summarized in Figures $1 A, 3 A$, and $6 A$ to compare the effects of different stress types. To achieve chronic VS resistant to habituation, mice experienced one stressor per day for $6 \mathrm{~d} /$ week for 4 weeks. Six stressors were used and the order, time of day (morning or afternoon), and location (testing room) were randomized, adapted as described previously (Alfarez et al., 2003; Teegarden and Bale, 2008). The six stressors included (1) long swim for 20 min in a $30^{\circ} \mathrm{C}$ water bath, (2) cold swim for $2.5 \mathrm{~min}$ in a $15^{\circ} \mathrm{C}$ water bath, (3) restraint for $15 \mathrm{~min}$ in a $50 \mathrm{ml}$ conical tube, (4) housed in isolation for $24 \mathrm{~h}$, (5) housed with soiled bedding for $24 \mathrm{~h}$, and (6) housed under lights-on conditions for $24 \mathrm{~h}$. In contrast, to achieve RI, mice were housed individually for 1 month and were restrained in a conical tube for $6 \mathrm{~h} / \mathrm{d}$ for $6 \mathrm{~d} /$ week in experiments 1 and 2 or $3 \mathrm{~h} / \mathrm{d}$ in experiment 4 . Nonstressed control mice were housed with same-sex littermates $(n=$ 3-5 per cage) and were transported to/from testing rooms but were not otherwise handled. Body weight of all mice was monitored at 0,2 , and 4 weeks during all the 1 month treatment periods.

Drug treatments. To achieve chronic hormone administration of corticosterone (CORT) in PS19 mice in experiment 3, subjects were implanted with slow-release, subcutaneous CORT pellets $(10 \mathrm{mg}, 21 \mathrm{~d}$ release) purchased from Innovative Research of America. This dose corresponds to an approximate dose of $12 \mathrm{mg} \cdot \mathrm{kg}^{-1} \cdot \mathrm{d}^{-1}$ and has been shown previously to induce physiological plasma CORT levels (Herrmann et al., 2009). PS19 mice were briefly anesthetized with isoflurane, shaved at the nape of the neck, and implanted with a hormone pellet, and the site was closed with surgical staples. Pellets were implanted on days 1 , 10, and 20, and animals were killed on day 30, as summarized in Figure $6 \mathrm{~B}$. Control mice were also anesthetized but received sham surgery where no pellet was implanted. This pellet administration schedule was based on results of a small pilot study in 6-month-old male WT mice ( $n=3$ per group). These pilot mice were implanted with corticosterone pellets, and $10 \mu \mathrm{l}$ of serum was collected from the tail $0.5,2,6,18$, and $24 \mathrm{~h}$ after injection and then on each subsequent day for $9 \mathrm{~d}$. Serum was then analyzed for CORT concentration.

The $\mathrm{CRF}_{1}$ antagonist NBI 27914 (NBI; Sigma) was chronically administered to a subset of PS19 mice in experiment 4 . These mice were administered a subcutaneous injection of $10 \mathrm{mg} / \mathrm{kg}$ NBI dissolved in a solution of DMSO/PEG400/ $\mathrm{dH}_{2} \mathrm{O}$. Injections occurred $15 \mathrm{~min}$ before onset of restraint stress. Vehicle-treated mice were also handled and underwent $\mathrm{RI}$ stress but were injected with DMSO/PEG400/ $\mathrm{dH}_{2} 0$. All mice underwent treatment $6 \mathrm{~d}$ /week for 4 weeks. The selectivity of NBI 27914 for the $\mathrm{CRF}_{1}$ receptor has been demonstrated because NBI has a much higher receptor affinity for $\mathrm{CRF}_{1}\left(K_{\mathrm{i}}=3.5 \mathrm{~nm}\right)$ over $\mathrm{CRF}_{2}\left(K_{\mathrm{i}} \geq 1000 \mathrm{nM}\right)$ (Hoare et al., 2004), and this NBI dose has been shown previously to be effective (Lee et al., 2009). NBI brain penetration was confirmed in a small pilot study. In this pilot, 7-month-old female WT mice $(n=3$ per group) were injected subcutaneously with $10 \mathrm{mg} / \mathrm{kg}$ NBI and killed 30 min, $2 \mathrm{~h}, 4 \mathrm{~h}$, or $8 \mathrm{~h}$ after injection. NBI concentrations in both plasma and brain were assessed to determine blood-brain barrier penetration, drug half-life in brain, and a standard brain/plasma pharmacokinetic profile.

Corticosterone assay. To evaluate the corticosterone response to acute stress, blood was collected before and after a $15 \mathrm{~min}$ restraint stress on the day the animals were killed for all mice in all treatment groups in experiments 1-3. After normal lights on (7:00 A.M.) and habituation from 7:00 A.M. to 8:00 A.M., mice were restrained in $50 \mathrm{ml}$ conical tubes, and blood was drawn at time $0,15,30$, and $90 \mathrm{~min}$ after $15 \mathrm{~min}$ restraint stress, as adapted by Teegarden and Bale (2008). Serum was frozen and later analyzed using a CORT enzyme immunoassay kit (catalog \#901097; Assay Designs) according to the instructions of the manufacturer.

Determination of plasma and brain NBI 27914 concentrations. Sample preparation and liquid chromatography tandem mass spectrometry (LC/ MS/MS) was conducted as described previously by our laboratory (Brunden et al., 2011). To prepare samples, $n=3$ brains per group were homogenized in $10 \mathrm{~mm}$ ammonium acetate, $\mathrm{pH} 5.7(1: 2 ; \mathrm{w} / \mathrm{v})$ using a handheld sonic homogenizer. NBI 27914 from $50 \mu \mathrm{l}$ of brain homogenate or plasma was extracted with $200 \mu \mathrm{l}$ of acetonitrile and centrifuged, 
and the supernatant was removed for LC/MS/MS analysis. The LC/ MS/MS system comprised an Aquity ultra performance liquid chromatographer (UPLC) and a tandem quadrupole mass spectrometer and was controlled using MassLynx software (Waters Corporation). Samples were separated on an Aquity BEH C18 column $(1.7 \mu \mathrm{m}, 2.1 \times 50 \mathrm{~mm})$ at $50^{\circ} \mathrm{C}$. The mobile phase A was $0.1 \%(\mathrm{v} / \mathrm{v})$ formic acid, and B was $0.1 \%$ $(\mathrm{v} / \mathrm{v})$ formic acid in acetonitrile. Injections of $5 \mu \mathrm{l}$ were separated at a flow rate of $0.6 \mathrm{ml} / \mathrm{min}$ using a gradient from 70 to $95 \%$ B over 2 min followed by wash and re-equilibration steps. NBI 27914 was detected in positive ionization mode using multiple reactions monitoring of specific collision-induced ion transitions and quantified by peak area. The MS was operated with a desolvation temperature of $450^{\circ} \mathrm{C}$ and a source temperature of $150^{\circ} \mathrm{C}$. Desolvation and source nitrogen gas flows were 900 and $50 \mathrm{~L} / \mathrm{h}$, respectively. Collision cell argon gas flow was $0.1 \mathrm{ml} / \mathrm{min}$. Source and analyzer voltages were optimized using the MassLynx auto tune utility. NBI 27914 standards at $1000 \mathrm{ng} / \mathrm{ml}$ in $50 \%$ acetonitrile were infused at $30 \mu \mathrm{l} / \mathrm{min}$ and combined with flow from the UPLC at 0.6 $\mathrm{ml} / \mathrm{min}$ and $50 \% \mathrm{~B}$. Standard curves were generated from spiked brain homogenate and plasma prepared at $0.01,0.1,1$, and $10 \mu \mathrm{m}$ and extracted as above. Peak area was plotted versus concentration, and a $1 / x$ weighed linear regression curve was used to quantify the unknowns.

Behavioral analysis. To evaluate anxiety-related behavior and cognitive learning and memory function, either before and/or after stress exposure, mice were tested in the elevated plus maze (EPM), Barnes maze test, and/or context and cued fear conditioning as summarized in Figures $1 A$, $3 A$, and $6 A$. In experiment 1 , all mice in all treatment groups were tested on all behavioral tasks. In experiment 2 , all mice in all treatment groups were tested on EPM and fear conditioning. In experiment 3, mice were only tested on EPM, and in experiment 4, mice were tested on fear conditioning. In all tests, mice were habituated to the testing room $1 \mathrm{~h}$ before tests, and the apparatus was cleaned with $70 \%$ ethanol between animals to minimize odor cues. To assess anxiety-related behavior, the EPM was conducted as described previously (Carroll et al., 2010) in which mice were allowed to explore the maze for $5 \mathrm{~min}$ and scored for percentage time spent in open arms. Mice were tested for hippocampal-dependent spatial memory on the Barnes maze (San Diego Instruments). On all testing days (days 1-6), mice were exposed to the Barnes maze for three $2.5 \mathrm{~min}$ trials, $15 \mathrm{~min}$ apart. Mice were tested on their ability to learn and remember the fixed position of this escape compartment, and their performance was scored for success rate and latency to find the escape compartment, as adapted from Patil et al. (2009) and described previously in our laboratory (Brunden et al., 2010). Also, to assess fear-related learning, mice were tested on the context and cued fear conditioning test (Med Associates). Mice were exposed to three repeats of an $80 \mathrm{~dB}$ tone paired with a $0.7 \mathrm{~mA}$ footshock. After $24 \mathrm{~h}$, mice were scored for percentage time freezing during a $5 \mathrm{~min}$ test in the same context, and, $48 \mathrm{~h}$ later, mice were scored for percentage time freezing during a 3 min tone exposure in a novel context (altered odor, flooring, and chamber shape), as adapted from Wellman et al. (2007).

A $\beta$ sandwich ELISA. Hippocampal and frontal cortex samples $(n=8$ per group) were homogenized in RIPA buffer $(0.5 \%$ sodium deoxycholate, $0.1 \%$ SDS, $1 \%$ Nonidet P-40, and 5 mm EDTA in TBS, pH 8.0) containing protease inhibitors $(1 \mu \mathrm{g} / \mathrm{ml}$ each of pepstatin A, leupeptin, L-1-tosylamido-2-phenylethyl chloromethyl ketone, 1-chloro-3tosylamido-7-amino-2-heptanone, soybean trypsin inhibitor, and 0.5 mM phenylmethylsulfonyl fluoride). Homogenates were sonicated and spun at $40,000 \times g$ for $30 \mathrm{~min}$ at $4^{\circ} \mathrm{C}$. The supernatant was collected, and the pellet was rehomogenized in $70 \%$ formic acid to a final concentration of $2 \mu \mathrm{l} / \mathrm{mg}$. Samples were sonicated and spun at $40,000 \times g$ for $30 \mathrm{~min}$ at $4^{\circ} \mathrm{C}$. $\mathrm{A} \beta_{1-40}$ and $\mathrm{A} \beta_{1-42}$ were detected using a sandwich ELISA protocol described previously (Lee et al., 2003). Briefly, Ban50 (anti-A $\beta_{1-10}$ ) was used as a capturing antibody coated in 384-well Nunc Maxisorp plates. After application of brain lysate samples overnight at $4^{\circ} \mathrm{C}$, horseradish peroxidase-conjugated BA-27 and BC-05 were incubated for $4 \mathrm{~h}$ to report $\mathrm{A} \beta$ species ending at positions 40 and 42 , respectively. Plates were washed, blocked, and exposed to reagents with a Thermo Scientific Multidrop 384 and a Bio-Tek Elx450 Select CW plate washer. For quantification of $A \beta$ levels, synthetic $A \beta_{1-40}$ and $A \beta_{1-42}$ purchased from Bachem
Biosciences were serially diluted to generate standard curves and read on a Spectra Max M5 plate reader.

Immunohistochemistry. Neutral Buffered Formalin was leeched from fixed hemibrains ( $n=6-10$ per group) after $24 \mathrm{~h}$ with Tris $/ \mathrm{NaCl}$, brains were paraffin embedded, and $6 \mu \mathrm{m}$ sections were cut and slide mounted. Slides were processed as described previously (Nakagawa et al., 1999; Yoshiyama et al., 2007). Briefly, sections were deparaffinized in xylene, hydrated in a series of ethanol and deionized water, quenched using a freshly prepared mixture of methanol $(150 \mathrm{ml})$ and hydrogen peroxide $(33 \%, 30 \mathrm{ml})$, washed in deionized water followed by $0.1 \mathrm{~m}$ Tris, blocked with $0.1 \mathrm{M}$ Tris $/ 2 \%$ fetal bovine serum, and incubated overnight in primary antibody at $4{ }^{\circ} \mathrm{C}$. The following antibodies were used in this study: $\mathrm{A} \beta_{1-11}$ (Nab228), 1:30,000; Ser202/Thr205 phosphorylated tau (ptau; AT8), 1:7500; activated microglia (Iba1), 1:10,000 (019-19741; Wako); neuronal nuclei (NeuN), 1:1000 (MAB377; Millipore), and anti-glucocorticoid receptor (GR), 1:300 (H-300: sc-8992; Santa Cruz Biotechnology). To complete immunohistochemistry (IHC), the avidin-biotin complex method was used according to the instructions of the vendor (Vector Laboratories) and processed using Biogenex reagents and the Biogenex 16000 automated staining system.

Triple immunofluorescence. Tissue was deparaffinized and washed as described above and subjected to antigen retrieval using boiling citrate treatment. Next, sections were stained with Thioflavin-S using a freshly made $0.0125 \%$ Thioflavin-S/40\% EtOH/60\% PBS solution, washed, and coincubated overnight at $4^{\circ} \mathrm{C}$ with primary antibodies Nab228 (monoclonal) and Iba1 (polyclonal). To complete immunofluorescent staining, sections were then coincubated with fluorescent secondary antibodies (FITC red anti-rabbit and AMCA blue anti-mouse, 1:200) and coverslipped using VectaShield antifade medium.

Immunoreactivity quantification. $\mathrm{A} \beta$, Iba1, and GR immunoreactivity (IR) in the frontal cortex and/or hippocampus were quantified by a researcher blinded to experimental condition using the IHC load technique as adapted from a previously described protocol (Carroll et al., 2007, 2010; Carroll and Pike, 2008). Load values were determined from selected $420 \times 330 \mu \mathrm{m}$ fields of immunolabeled sections that were captured and digitized using a video capture system (Nikon camera coupled to an Olympus DP71 upright microscope). Using NIH Image J software, digital grayscale images were converted into binary positive/negative data using a constant threshold limit. The percentage of positive pixels (i.e., immunoreactive area) was quantified for each image to generate immunoreactive load values (i.e., percentage area occupied by the immunoreactivity). For GR-IR in the CA1 of hippocampus, three sequential sections of hippocampus were analyzed/brain. The capture frame was centered over the pyramidal layer with the captured field corresponding from between the narrow zone that marks the division between the end of the regio inferior $(\mathrm{CA} 2 / 3)$ and the start of regio superior (CA1) and the beginning of the subiculum, as defined previously (West et al., 1991). Each of the three images per brain were analyzed, and load values were averaged. For $\mathrm{A} \beta$-IR in the hippocampus, one field of classic hippocampus was captured from each of three sequential sections per brain. The capture field was drawn freehand around the entire hippocampus corresponding to the region from the posterior $\mathrm{CA} 2$ to the anterior subiculum and from the ventral tip of dentate gyrus to the dorsal arch of the CA1. Each freehand drawn hippocampus was analyzed, and load values were averaged. The same method was applied for $A \beta$ and Ibal-IR in the frontal cortex, but the quantification field was held constant $(50 \times 75 \mu \mathrm{m})$. Here, fields were centered over layers $4-5$, beginning in cingulate cortex area 1 and progressing laterally to somatosensory cortex as described previously (Carroll et al., 2007). To achieve the ratio of Iba1-IR/Nab228IR, identical quantification fields were overlaid on adjacent sections stained with each nonfluorescent antibody. Thus, quantification of each antibody was achieved on the exact same quantification field.

To quantify neurofibrillary tangle-like inclusions, AT8-IR, and degeneration in the hippocampus, digital pictures were taken of the hippocampus (every fifth longitudinal section was analyzed across the entire hippocampus, a total of $\sim 10$ sections per brain), beginning with a randomly selected section of dorsal hippocampus. AT8-IR aggregates were counted within the hippocampal formation as those tau inclusions stained thoroughly with AT8-IR and dystrophic neuronal processes. 


\section{A Experiment 1: WT and Tg2576 F}

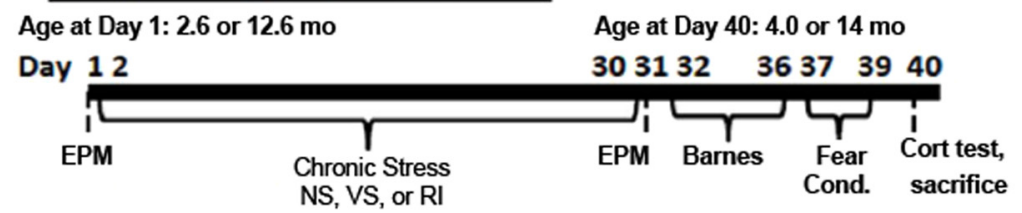

B NS


E

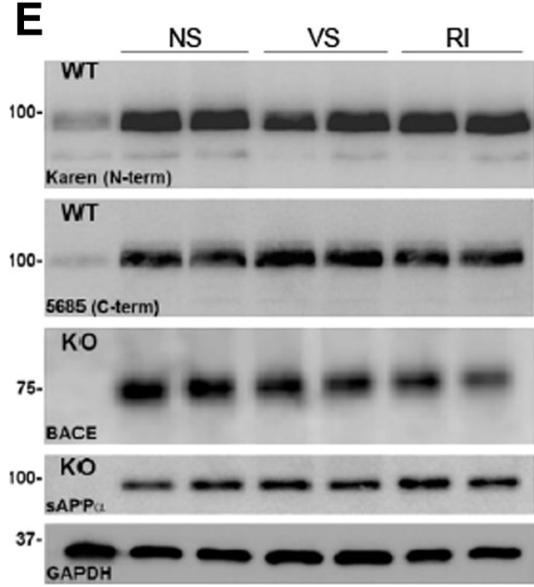

vs

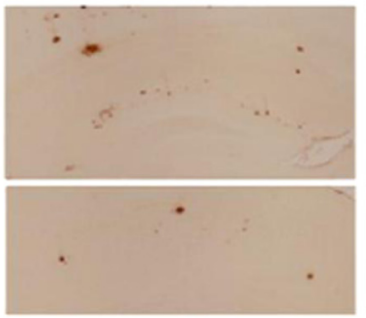

RI

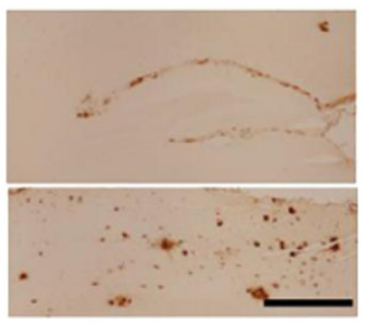

F<smiles>[123I-]</smiles>

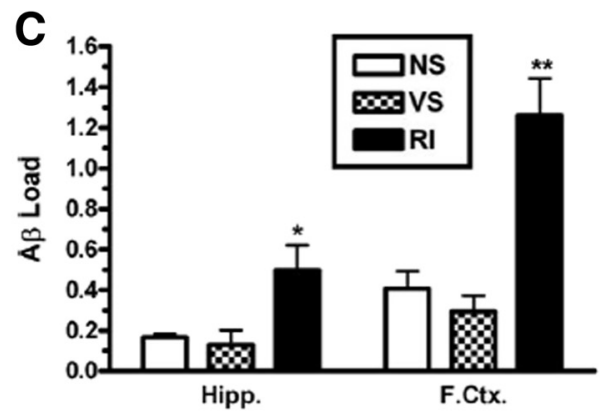

D

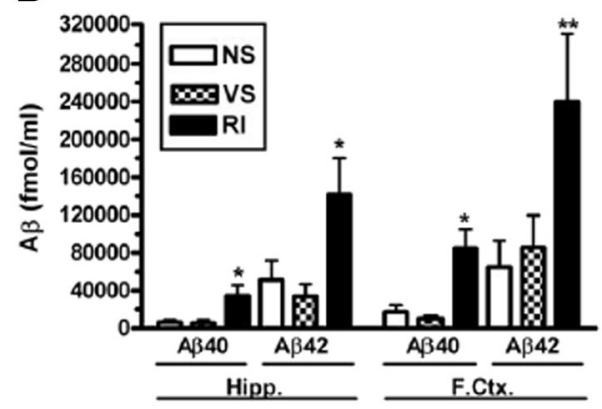

Figure 1. Chronic RI stress exacerbates A $\beta$ levels in stress-sensitive Tg2576 mice. $A$, Experimental design of experiment 1; WT and Tg2576 female mice ( $n=10$ per group) were exposed to NS, VS, or RI stress for 1 month. $\boldsymbol{B}$, Representative images in the hippocampus (Hipp.) and frontal cortex (F.Ctx.) show increased A $\beta$-IR in RI mice, quantified in $C\left(F_{(3,18)}=5.61, p=0.014 ;\right.$ and $F_{(3,24)}=$ $15.64, p<0.0001)$. Data show mean \pm SEM A $\beta$ load. $\boldsymbol{D}$, By ELISA, insoluble $A \beta_{40}$ was significantly increased by Rl in the hippocampus $\left(F_{(5,28)}=4.47, p=0.005\right)$ and frontal cortex $\left(F_{(5,28)}=2.08\right.$, $p=0.11)$, as was $A \beta_{42}$ in the hippocampus $\left(F_{(2,21)}=6.51, p=0.007\right)$ and frontal cortex $\left(F_{(2,15)}=12.4, p=0.001\right)$. Data show mean \pm SEM A $\beta$ levels $(n=8$ per group). $E$, Hippocampal protein levels of APP, SAPP $\alpha$, and BACE were measured with either WT or BACE KO mouse hippocampal homogenate ( $n=2$ per group) as a negative control. In 14 -month-old Tg2576 mice, neither stress altered hippocampal levels of 5685, Karen, BACE, or sAPP. F, CORT levels were plotted over time after an acute 15 min restraint stress (arrow) in 4-month-old WT and Tg2576 mice. In WT mice, both $\operatorname{VS}\left(F_{(5,28)}=4.9, p=0.05\right)$ and RI stress $\left(F_{(2,20)}=1.3, p=0.31\right)$ decreased the area under the curve compared with NS. However, CORT levels were elevated significantly in all conditions of Tg2576 mice, regardless of stress treatment. Data show mean $\left(n=10\right.$ per group). ${ }^{*} p<0.05$, ${ }^{* *} p<0.01$ from NS. Scale bar, $0.5 \mathrm{~mm}$.

Subregional AT8-IR was quantified in seven subregions of hippocampus and six cortical layers using a semiquantitative scale (Stage $0-5$ of increasing IR presence and intensity) as modified from a previously described paradigm in our laboratory (Hurtado et al., 2010). Degeneration was scored using the same semiquantitative scale (Stage $0-5$ of increasing cell loss).

Western blots. To measure soluble proteins, hippocampal and frontal cortex samples ( $n=2-6$ per group) were homogenized in RIPA buffer in the presence of protease inhibitors and briefly sonicated. Samples were centrifuged at $40,000 \times g$ for $30 \mathrm{~min}$ at $4^{\circ} \mathrm{C}$, and protein was measured by bicinchoninic acid assay. To measure insoluble tau, the supernatant was collected and the pellet was rehomogenized in $70 \%$ formic acid to a final concentration of $2 \mu \mathrm{l} / \mathrm{mg}$. Samples were sonicated and spun at 40,000 $\times$ $g$ for $30 \mathrm{~min}$ at $4^{\circ} \mathrm{C}$. Later, $15 \mu \mathrm{g}$ of protein was electrophoresed on $10 \%$ Tris-glycine acrylamide gels and transferred to a nitrocellulose membrane. Immunoblots were probed with the following antibodies: N-terminal APP (Karen), 1:1000; C-terminal APP (5685), 1:1000; $\beta$-secretase cleavage enzyme (BACE), 1:1000; soluble APP $(\operatorname{sAPP} \alpha), 1: 1000$; Ser396/Ser404 ptau (PHF1), 1:1000; total human tau (17025), 1:1000; non-phosphorylated tau (Tau 1), 1:1000; total mouse tau (T49), 1:1000; and a loading control (GAPDH), 1:2000. As a negative control to demonstrate
BACE antibody specificity, hippocampal homogenate from a BACE knock-out (KO) mouse (Luo et al., 2001) was also probed when appropriate. Immunoblots were then exposed to species-specific horseradish peroxidase-conjugated anti-IgG antibodies (Santa Cruz Biotechnology) and visualized by enhanced chemiluminescence (PerkinElmer Life and Analytical Sciences) using a Fuji Imager. Images were quantified using Multi Gauge version 3.2 FujiFilm software.

Statistical analysis. To statistically evaluate treatment effects, raw data were first analyzed by ANOVA and then subjected to between-group comparisons using the Bonferroni's post hoc test. Effects achieving 95\% probability (i.e., $p<0.05$ ) were interpreted as statistically significant. Barnes maze was analyzed using repeated-measures ANOVA.

\section{Results}

Experiment 1: Establishment of a chronic stress model capable of exacerbating pathology in $\mathrm{Tg} 2576$ mice

Two cohorts of Tg2576 and WT littermate control mice were exposed to NS, VS, or RI stress for 1 month and were subsequently killed at either 4 or 14 months of age (Fig. $1 \mathrm{~A}$ ). To ensure that stress did not affect general health, mice were monitored 
daily and weighed at 0,2 , and 4 weeks of stress. No body weight differences were observed between the NS and stress groups in either 4-month-old $\left(F_{(5,39)}=2.97, p=0.23\right)$ or 14-month-old $\left(F_{(5,42)}=4.41, p=0.46\right)$ WT cohorts. To ensure that both VS and RI stress paradigms induced sufficient stress, adrenal gland weight was measured and found to be significantly greater in the VS and RI WT cohorts than in the NS WT mice at both 4 months $\left(F_{(5,44)}=4.93, p=0.0014\right)$ and 14 months $\left(F_{(5,48)}=6.25, p<\right.$ $0.0001)$ of age.

After 1 month of stress, Tg2576 mice were killed and assessed for levels of $\mathrm{A} \beta$ by both IHC and sandwich ELISA. Figure $1 B$ shows representative examples of $A \beta$-IR load, as assessed by quantification of $\mathrm{A} \beta \mathrm{IHC}$, in both hippocampus and frontal cortex of 14-month-old Tg2576 mice exposed to NS, VS, and RI. Quantification of the A $\beta$-IR load values revealed that mice exposed to RI displayed significantly greater $A \beta$-IR compared with NS, whereas VS mice displayed no change (Fig. $1 C$ ). Furthermore, insoluble levels of $\mathrm{A} \beta_{42}$ were also measured by ELISA in both frontal cortex and hippocampus. In 14-mongh-old Tg2576 mice, RI treatment significantly increased $\mathrm{A} \beta_{40}$ and $\mathrm{A} \beta_{42}$ levels compared with NS in both brain regions (Fig. $1 D$ ). Again, VS mice displayed no change in $\mathrm{A} \beta$ levels. The same trend was also demonstrated in 4-month-old Tg2576 mice. Although these mice have not yet developed appreciable $\mathrm{A} \beta$ load levels, soluble $\mathrm{A} \beta_{40}$ levels in both the frontal cortex $\left(F_{(2,27)}=8.78, p=0.0001\right)$ and hippocampus $\left(F_{(5,27)}=5.22, p=0.0026\right)$ were strongly increased in RI $(p<0.01)$ but not VS mice, relative to NS mice. These data demonstrate that chronic RI stress, but not VS, exacerbates levels of $\mathrm{A} \beta$ in $\mathrm{Tg} 2576$ mice.

To investigate potential mechanisms by which RI stress exacerbates $\mathrm{A} \beta$ accumulation, we evaluated indices of APP production and proteolytic processing by Western blot (Fig. $1 E$ ). In 14-month-old Tg2576 mice, neither VS nor RI stress altered hippocampal levels of APP detected with a C-terminal (5685) antibody $\left(F_{(2,5)}=8.01, p=0.53\right)$, an N-terminal (Karen) antibody $\left(F_{(2,5)}=2.05, p=0.83\right)$, or an antibody that detects secreted APP cleaved at the $\alpha$-secretase site $(\operatorname{sAPP} \alpha)\left(F_{(2,5)}=1.88, p=0.30\right)$, suggesting that stress does not lead to higher APP production or non-amyloidogenic cleavage products. Furthermore, neither VS nor RI stress altered hippocampal levels of BACE cleavage products of $\operatorname{APP}\left(F_{(2,5)}=3.19, p=0.75\right)$ compared with a BACE KO mouse as a negative control to demonstrate antibody specificity. This result suggests that stress does not induce altered APP processing at this site. Furthermore, stress did not alter the levels of neprilysin, an $\mathrm{A} \beta$ degrading enzyme (data not shown).

Finally, to investigate the relationship between $\mathrm{A} \beta$ accumulation and HPA function, we measured serum CORT levels in response to an acute restraint after 1 month of chronic stress. The 4-month-old, WT, naive, NS mice displayed a striking but transient increase in CORT after a 15 min acute restraint stress that returned to baseline within $90 \mathrm{~min}$ (Fig. $1 F$ ). However, young WT mice previously exposed to 1 month of chronic VS or RI stress display a significantly blunted CORT response, characterized by smaller area under the curve (data not shown), as well as a smaller CORT peak and rise rate. The blunted CORT response to an acute stressor in rats with a history of chronic stress is consistent with previous reports (Watanabe et al., 1992; Magariños and McEwen, 1995). In contrast, young Tg2576 mice displayed a significantly higher CORT peak than their WT littermates, and the CORT responses were not blunted by previous exposure to VS or RI stress (Fig. $1 F$ ). This effect was masked in 14-month-old mice, because all mice displayed a maximal CORT response regardless of treatment group or genotype (data not shown). This is consistent with previous studies demonstrating altered HPA responsiveness in aging rodents (Bao et al., 2008). Together, these data suggest that even a relatively low level of $\mathrm{A} \beta$ accumulation is associated with a heightened HPA sensitivity and a weakened ability to habituate to chronic stress. Although the hypothalamus, the central controller of the CORT response, is generally spared from $\mathrm{A} \beta$ accumulation in $\mathrm{AD}$, these data suggest that the regulation of hypothalamic function by the hippocampus and cortical regions may be disrupted in this mouse model.

To address the mechanism of increased $A \beta$ in the absence of increased APP levels, we examined microglia activation to determine whether chronic stress might suppress $\mathrm{A} \beta$ clearance through an alteration of microglia phagocytosis. We analyzed activated microglia levels by Iba1 IHC in the frontal cortex of 14-month-old Tg2576 and WT mice (Fig. $2 A, B$ ). In WT mice, no change in Ibal load in the frontal cortex was observed between different stress conditions $\left(F_{(2,22)}=6.47, p=0.81\right)$. In Tg2576 mice, although activated microglia were strongly associated with Thioflavin-S ${ }^{+} \mathrm{A} \beta$ plaques in NS mice and VS mice, RI mice demonstrated a strong trend toward a lower ratio of Thioflavin $-\mathrm{S}^{+}$to total $\mathrm{A} \beta$ plaque load $(p=0.18)$. Interestingly, a determination of load values for Ibal and Nab228 in adjacent sections revealed that the ratio of activated microglia to $A \beta$ deposits was significantly lower in RI mice, an effect driven by the increase in $\mathrm{A} \beta$ despite unchanged Iba1-IR levels in the same area (Fig. $2 B$ ). Furthermore, this effect was specific to Tg2576 mice with $\mathrm{A} \beta$ deposits because neither VS nor RI significantly altered Iba1 load values in PS19 mice $\left(F_{(5,37)}=9.44, p=0.47\right)$. These observations suggest a failure in RI mice to recruit and/or activate microglia at $\mathrm{A} \beta$ deposits.

To evaluate whether the stress models affect spatial memory and fear-related memory, WT and Tg2576 mice were tested on the Barnes maze and for both context and cued fear conditioning (Fig. $2 C, D)$. We observed a significant overall RI stress effect in the Barnes maze, because 14-month-old RI stressed Tg2576 mice had a lower success rate (Fig. 2C) and took significantly longer to find the target (increased latency) $\left(F_{(5,35)}=5.99, p=0.006\right)$ compared with NS mice, whereas VS mice displayed no spatial memory impairment compared with NS mice. Both VS and RI Tg2576 mice displayed a significant impairment (lower percentage freezing) on both context and cued fear conditioning compared with NS mice (Fig. 2D). Importantly, these stress-induced differences were not observed in 14month-old WT mice, because there was no effect of either stress on the Barnes maze success $\left(F_{(2,17)}=1.18, p=0.33\right)$ and latency measures $\left(F_{(2,17)}=1.84, p=0.19\right)$. Furthermore, WT mice under different stress conditions were indistinguishable on both context $\left(F_{(2,24)}=5.86, p=0.48\right)$ and cued $\left(F_{(2,24)}=1.54, p=0.24\right)$ fear conditioning. These data suggest that both the stress-induced spatial and fear-associated memory deficits observed in RI Tg2576 mice are related to increased brain $\mathrm{A} \beta$ levels. Our data also suggest the possibility that VS differentially impairs fear memory through a pathway that occurs before overt $\mathrm{A} \beta$ deposition such as synaptic plasticity disruption.

\section{Experiment 2: Effects of stress on hyperphosphorylated tau, aggregated tau inclusions, neurodegeneration, and fear-related memory in PS19 mice}

Having established a model of chronic stress capable of exacerbating AD-related neuropathology in Tg2576 mice, we sought to apply this paradigm to a previously characterized Tg mouse model in which tau hyperphosphorylation, pathological aggregated tau inclusions, and neurodegeneration develop with age. A 
A
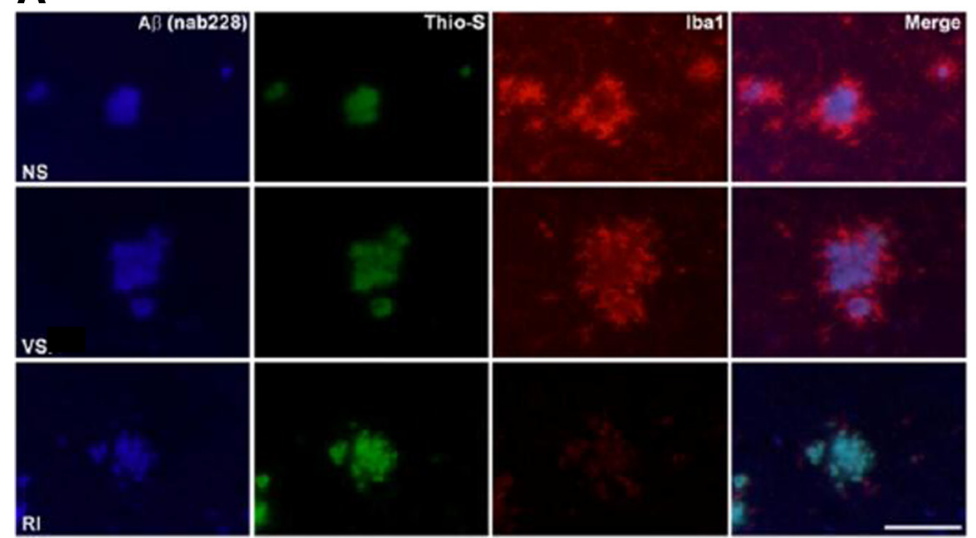

C

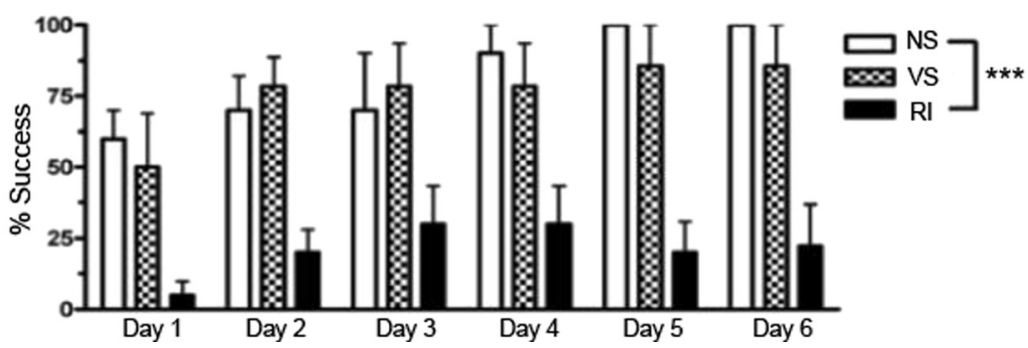

B

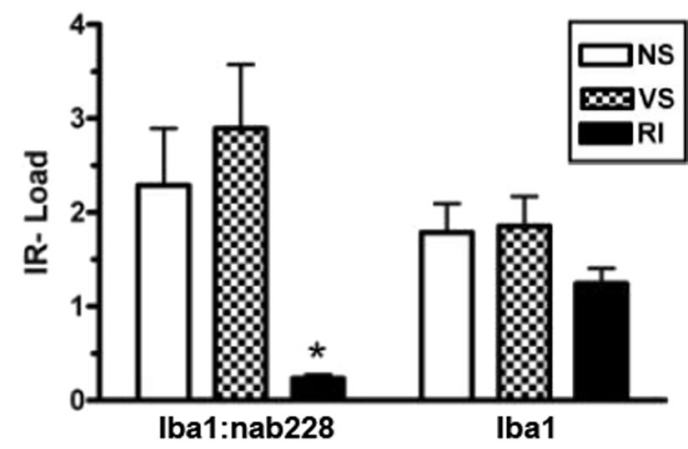

D

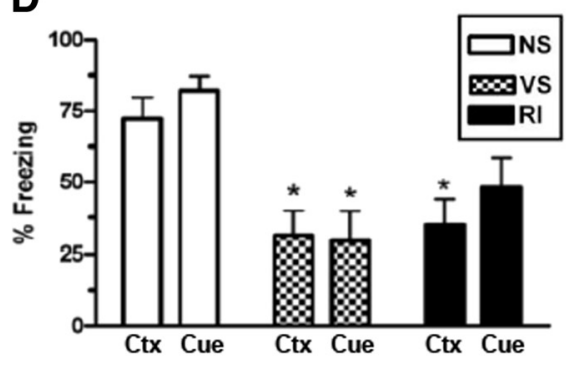

Figure 2. Chronic stress impairs spatial and fear-related learning but does not correlate with activated microglia-associated A $\beta$ plaques in Tg2576 mice. Tg2576 mice were assessed for activated microglia associated with $A \beta$ plaques. $A$, Representative images show that, regardless of stress condition, all mice display Nab228-IR A $\beta$ plaques (blue) that are Thioflavin- $S^{+}$(green) in the frontal cortex. However, RI mice showed significantly less Iba1-IR activated microglia (red) around A $\beta$ plaques without a decrease in overall Iba1-IR. $\boldsymbol{B}$, This effect is quantified by nonfluorescent immunoreactivity load ratios (mean \pm SEM) of adjacent sections $\left(F_{(2,21)}=6.51, p=0.007\right.$; and $F_{(2,21)}=6.51, p=0.007 ; n=8$ per group). Fourteen-month-old Tg2576 mice ( $n=10$ per group) were also tested on the Barnes maze $(\boldsymbol{C})$ and fear conditioning $(\boldsymbol{D})$. RI but not VS mice demonstrated significantly worse percentage success $\left(F_{(3,35)}=12.8, p<0.0001\right)$ compared with NS mice. In both context (Ctx) $\left(F_{(2,20)}=6.22, p=0.009\right)$ and cued $(C u e)\left(F_{(2,21)}=5.98, p=0.01\right)$ fear conditioning, both VS and RI stressed Tg2576 mice froze significantly less than NS mice. Data show mean \pm SEM. ${ }^{*} p<0.05,{ }^{* * *} p<0.001$ from NS. Scale bar, $100 \mu \mathrm{m}$.

cohort of PS19 and WT littermate control mice were exposed to NS, VS, or RI stress $(6 \mathrm{~h} / \mathrm{d})$ for 1 month and killed at 6 months of age (Fig. 3A), at which point the PS19 normally begin to show modest tau pathology. No body weight differences were observed between treatment groups $\left(F_{(5,56)}=2.01, p=0.09\right)$ in WT mice, indicating that stress did not affect general health. To ensure that both VS and RI stress paradigms induced sufficient stress, adrenal gland weight was measured in WT mice and found to be stress regulated $\left(F_{(5,56)}=4.15, p=0.003\right)$ and significantly greater after VS and RI relative to NS. Furthermore, EPM performance in WT mice was measured as a reflection of anxiety and found to be stress regulated $\left(F_{(5,54)}=6.11, p=0.0002\right)$ because both WT VS and RI mice demonstrated higher anxiety compared with WT NS mice (data not shown).

After 1 month of stress, PS19 mice were assessed for levels of tau hyperphosphorylation by both IHC and Western blot (Fig. $3 B-D$ ), as well as neurofibrillary tangle-like inclusions (Fig. $3 C$ ). Figure $3 B$ shows representative examples of AT8-IR in both the hippocampus (specifically in the mossy fibers, hilus, and dentate gyrus) and frontal cortex. Quantification of AT8-IR neurofibrillary tangle-like inclusions (inset) revealed that RI stressed mice displayed significantly more ptau in the hippocampus by IHC, whereas VS stressed mice displayed no change (Fig. $3 B, C$ ). In addition, subregional quantification of AT8-IR using a semiquantitative rating scale $(0-5)$ revealed that the most vulnerable hippocampal areas with the highest ptau scores were the mossy fibers (1.07 \pm 0.2$)$, hilus $(0.93 \pm 0.1)$, and dentate gyrus $(0.43 \pm 0.1)$, and the most vulnerable cortical area was layer $1(1.17 \pm 0.2)$. The subiculum (0.28 \pm 0.1$),$ CA1 $(0.35 \pm 0.1)$, CA2 (0.26 \pm 0.1$),$ CA3 (0.39 \pm $0.1)$, and cortical layer $6(0.07 \pm 0.0)$ were rarely affected. However, this pattern persevered regardless of stress condition, suggesting that, although subregions of the hippocampus and cortex are differentially vulnerable to tau pathology, chronic stress does not induce additional subregional vulnerability.

Furthermore, levels of soluble and insoluble tau phosphorylated at Ser396 and Ser404 were assessed by PHF1 Western blots. PHF1 levels were normalized to total tau, as determined with the 17025 antibody, and showed significantly higher levels in RI, but not VS, stressed mice compared with NS controls. However, no change was observed in levels of a total tau when normalized to GAPDH $\left(F_{(2,5)}=1.42, p=0.37\right)$ (Fig. $\left.3 D\right)$. These data demonstrate that chronic RI, but not VS stress, exacerbates both soluble and insoluble levels of pathologic ptau in PS19 mice, similar to the enhanced pathology induced by RI stress in Tg2576 mice.

To evaluate whether stress induced deficits in fear-related memory, both WT and PS19 mice were tested for both context and cued fear conditioning (Fig. $3 E$ ). In both fear conditioning tests, significant overall group differences were observed. PS19 mice showed a statistically significant impairment in both context and cued fear conditioning after chronic RI, and the VS mice demonstrated a significant deficit in contextual fear conditioning, as well as a trend toward impaired performance in cue conditioning that did not reach statistical significance. In contrast, WT mice displayed only a nonsignificant trend toward impaired 

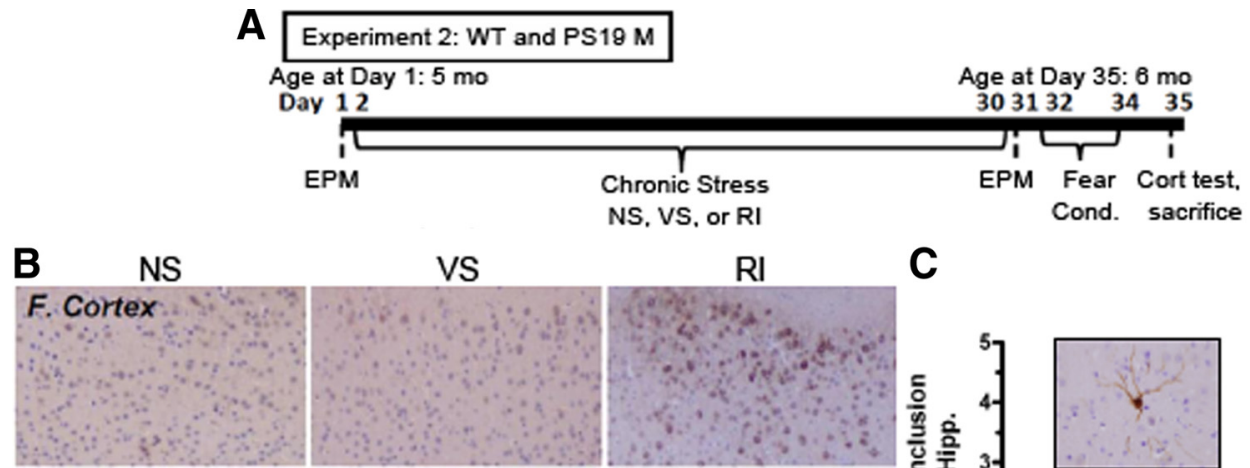

C
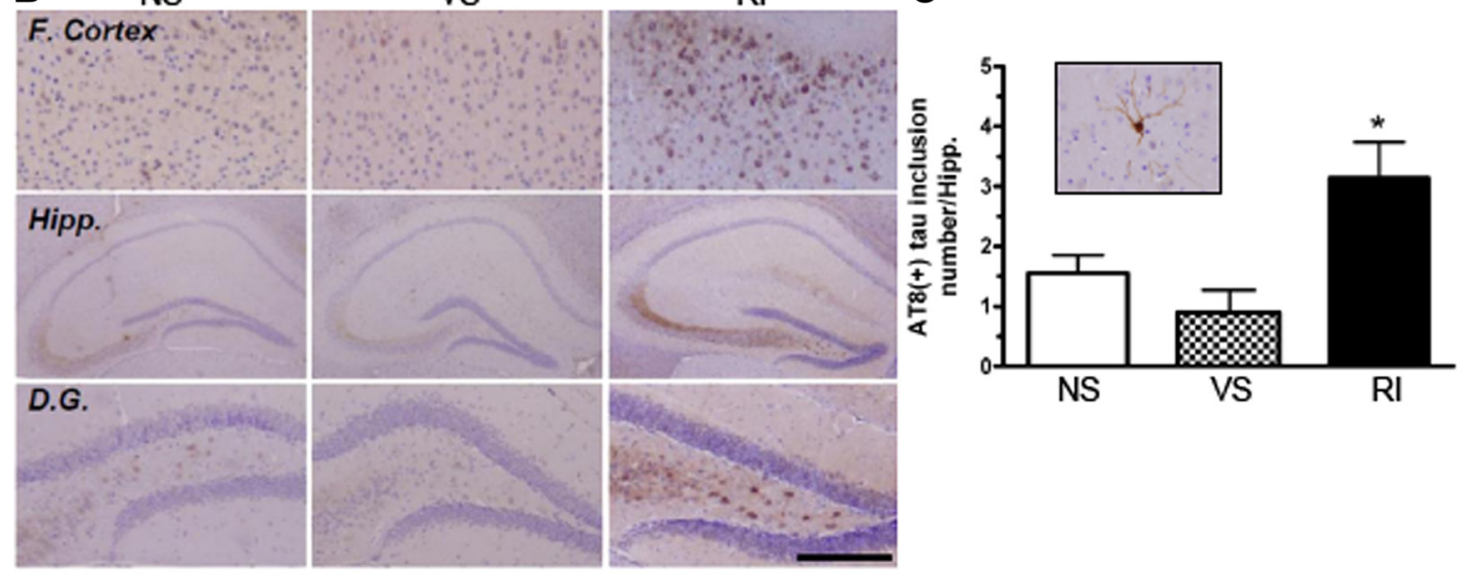

E
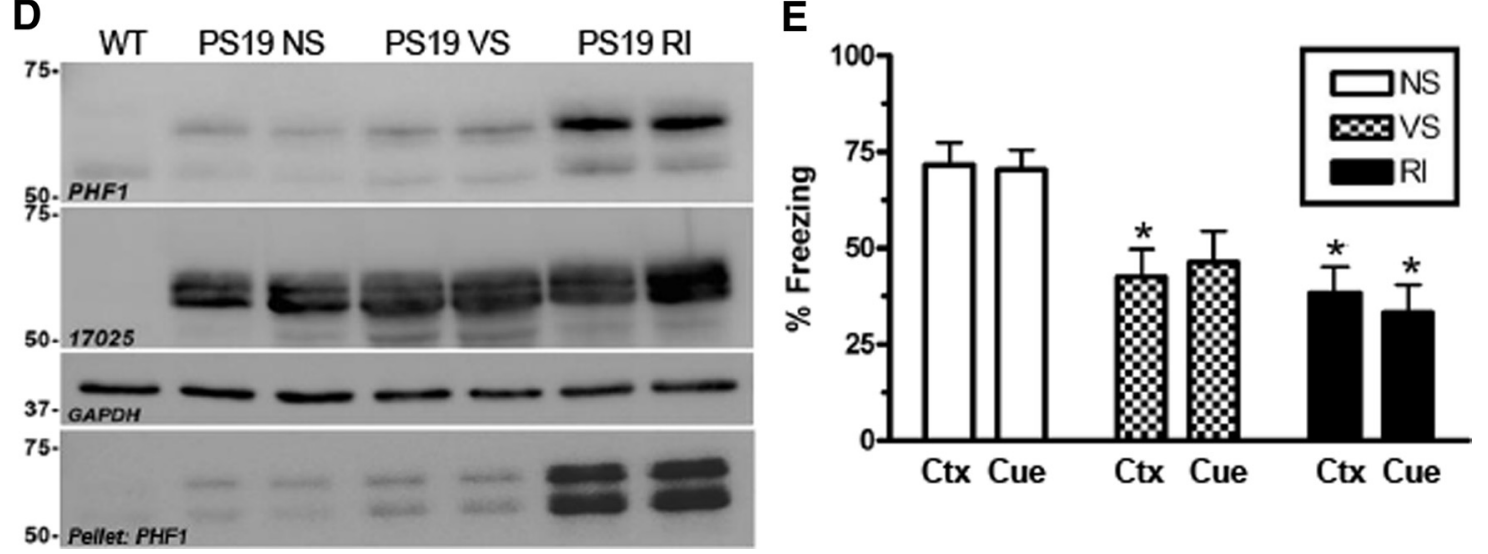

Figure 3. Chronic Rl stress exacerbates hyperphosphorylated tau, aggregated tau inclusions, and fear-related memory in PS19 mice. $A$, Experimental design of experiment 2; WT and PS19 male mice ( $n=8$ per group). $\boldsymbol{B}$, Representative images demonstrate that, in the frontal cortex (F. Cortex) and the hippocampus (Hipp.), specifically the dentate gyrus (D.G.), chronic RI increased AT8-IR compared with NS. C, The number of AT8-IR tau inclusions (inset) in the hippocampus was counted and showed a significant increase in RI compared with NS mice $\left(F_{(2,23)}=14.42, p<0.0001\right)$. Data show mean \pm SEM number of tau inclusions. $D$, Tau was also evaluated by Western blot using both PHF1 and 17025 antibodies and probed for GAPDH as a loading control. PS19 RI stressed mice displayed a significant increase in soluble PHF1 $\left(F_{(2,5)}=8.21, p=0.0024\right)$ and insoluble $\left(F_{(2,5)}=1.96, p=0.009\right)$ but not 17025 expressions in the hippocampus. E, PS19RI mice showed significant impairment compared with NS mice in both context (Ctx) $\left(F_{(5,54)}=3.88, p=0.0048\right)$ and cued (Cue) fear conditioning $\left(F_{(5,54)}=4.19, p=0.003\right) .{ }^{*} p<0.05$, from NS of same genotype. Scale bar (in $\boldsymbol{B}): 0.5 \mathrm{~mm}$ for cortex and hippocampus; $200 \mathrm{~mm}$ for dentate gyrus.

freezing behavior after either VS or RI stress in both context $\left(F_{(2,28)}=2.72, p=0.25\right)$ and cued $\left(F_{(2,26)}=1.52, p=0.09\right)$ fear conditioning. These data suggest that the decreased cognitive performance in the RI stressed PS19 mice is associated with the exacerbated tau pathology observed in these animals.

To evaluate the effects of chronic stress on neurodegeneration, we completed a semiquantitative analysis of hippocampal degeneration by NeuN immunohistochemistry in the PS19 mice and also measured hemi-hippocampal weight in WT and PS19 mice. We observed that RI, but not VS, chronic stress induced cell loss in the hippocampus of PS19 mice compared with NS mice (Fig. 4A), and these were statistically significant results when analyzed using a semiquantitative rating scale of degeneration (Fig. $4 B$ ). Furthermore, hemi-hippocampal weights were measured and found to be significantly lower in PS19 RI mice compared with NS or VS PS19 or WT mice (Fig. 4C), suggesting that PS19 RI mice are susceptible to neurodegeneration.
To investigate the relationship between tau hyperphosphorylation and HPA function, we measured serum CORT levels in response to an acute stress after 1 month of chronic stress. Consistent with our findings in experiment 1, WT NS mice again displayed a striking but transient increase in CORT after a $15 \mathrm{~min}$ acute restraint stress that returns to baseline within $90 \mathrm{~min}$ (Fig. $4 D$ ). However, WT mice previously exposed to 1 month of chronic VS or RI stress display a significantly blunted CORT response, characterized by smaller area under the curve (Fig. $4 D$ ). In contrast, NS and VS PS19 mice displayed a somewhat delayed CORT peak relative to their WT littermates, and the CORT response in the PS19 mice appeared to be independent of their previous stress exposure (Fig. $4 D$ ). These data suggest that tau hyperphosphorylation alters HPA sensitivity and weakens the ability for PS19 mice to habituate to chronic stress.

To further investigate the effect of stress in the brain, we analyzed the level of GR, the most prominent corticosterone receptor, in the 




B
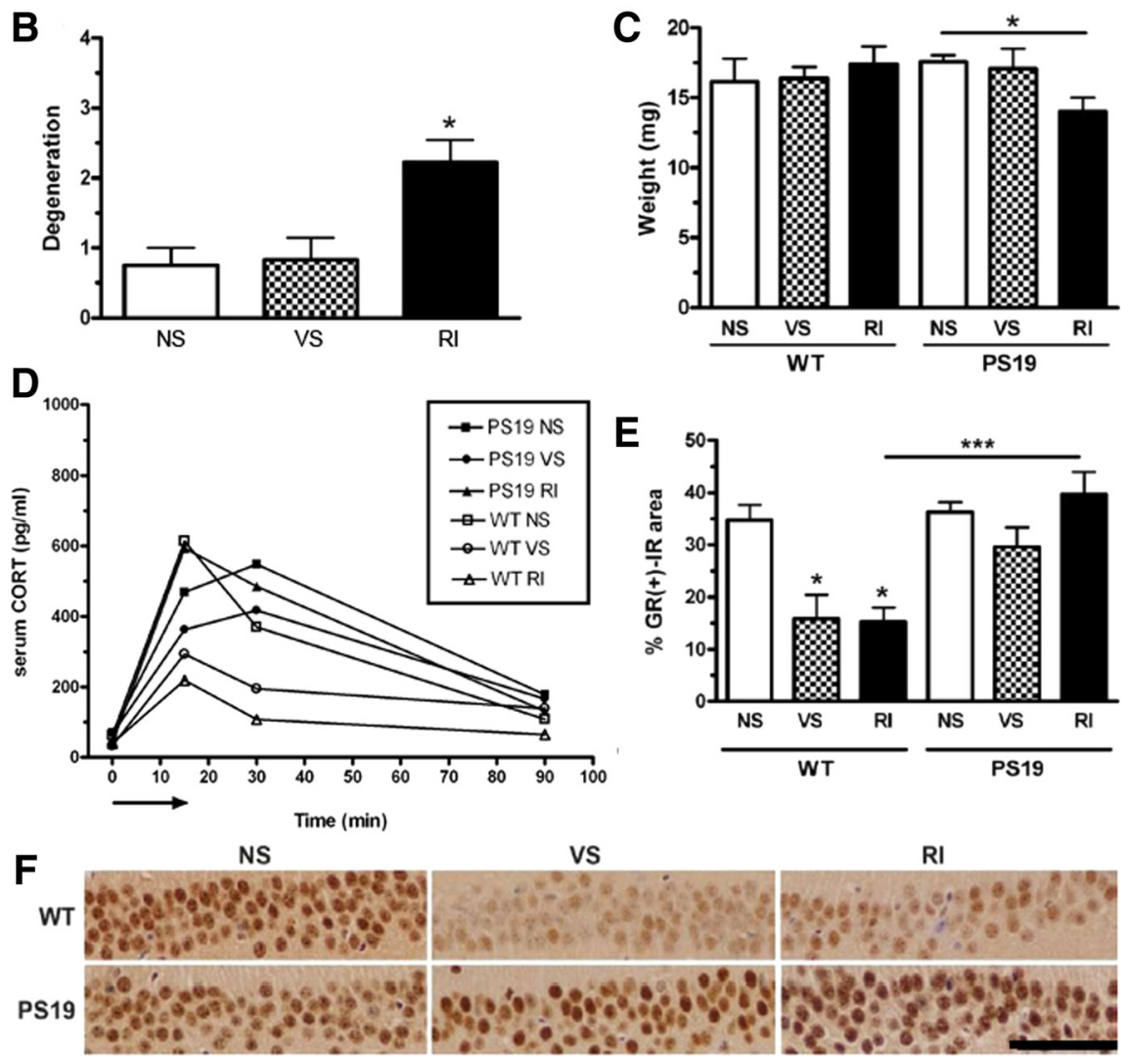

Figure 4. Chronic RI stress induces neurodegeneration, altered GR expression, and altered corticosterone response in PS19 mice. PS19 mice were evaluated for hippocampal neurodegeneration. $\boldsymbol{A}$, Representative pictomicrographs of NeuN-IR show that PS19 RI mice displayed significantly higher degeneration as quantified in $\boldsymbol{B}\left(F_{(2,18)}=6.89, p=0.007\right)$. C, Hemi-hippocampal weight assessment also revealed that PS19 (but notWT) RI mice displayed lowerhippocampal weight $\left(F_{(2,21)}=3.62, p=0.04\right)$ compared with VS or NS mice. Data show mean \pm SEM ( $n=8$ per group). ${ }^{*} p<0.05$ from NS. Scale bar, $0.5 \mathrm{~mm}$. D, CORT levels were plotted over time after an acute $15 \mathrm{~min}$ restraint stress (arrow). In WT mice, both VS $\left(F_{(2,18)}=24.7, p<0.001\right)$ and $\operatorname{RI}\left(F_{(2,18)}=24.7, p<0.001\right)$ stress decreased the area under the curve compared with NS. However, CORT levels were elevated significantly in all conditions of PS19 mice, regardless of stress treatment. Data show mean ( $n=10$ per group). $\boldsymbol{F}$, These mice were also assessed for GR-IR in the CA1. Representative pictomicrographs of both WT and PS19 mice under different stress conditions show that VS and RI significantly reduced GR levels in WT but not PS19 mice. $\boldsymbol{E}$, This effect was quantified to demonstrate a significant group effect $\left(F_{(5,25)}=11.6, p<0.0001\right)$. Data show mean \pm SEM GR-IRload. ${ }^{*} p<0.05$, and ${ }^{* * *} p<0.001$. Scale bar, $50 \mu \mathrm{m}$.

hippocampus of WT and PS19 mice by IHC (Fig. 4E,F). This brain region is particularly vulnerable to tau pathology, and we observed interesting differences in GR expression. In WT mice, both chronic VS and RI stress cause a significant decrease in GR-IR in the CA1 compared with NS naive WT mice (Fig. $4 F$ ), which is consistent with the implication that WT mice are able to habituate to chronic stress and display a blunted HPA response when challenged with an acute stress. In contrast, in PS19 mice, both VS and RI mice maintained a high level of $\mathrm{GR}^{+}$-IR in the hippocampus. This suggests that GRs are unable to habituate to chronic stress in the PS19 mice and thus raises the possibility that excessive signaling through the GR may be involved in stress-induced enhancement of tau hyperphosphorylation.
RI

Experiment 3: CORT involvement in stress-induced tau hyperphosphorylation in PS19 mice

Based on the glucocorticoid hypothesis of brain aging, which proposes that chronic exposure to stress and/or glucocorticoids promotes hippocampal aging and even $\mathrm{AD}$ pathogenesis (Landfield et al., 2007), we sought to mimic RI stress-induced changes on tau phosphorylation using direct CORT administration. Nonstressed, male PS19 mice at 8 months of age were evaluated for changes in ptau after 1 month of chronic CORT administration (Fig. 5A). A separate group of control mice received subcutaneous pellets containing vehicle only. In a small pilot study, CORT treatment induced a significant spike in serum CORT levels, suggesting that the pellets released an initial bolus of corticosterone into the bloodstream. However, at $72 \mathrm{~h}$ after implantation, mice still maintained a CORT level that was higher than a pre-stress, baseline CORT measurement in PS19 mice $(\sim 50 \mathrm{pg} / \mathrm{ml})$ (Fig. 5B). This treatment did not cause any significant changes in body weight $\left(F_{(5,5)}=2.6, p=0.93\right)$, suggesting that it was well tolerated. However, PS19 mice treated with chronic CORT were indistinguishable from vehicle-treated mice with regard to the level of AT8-IR in the hippocampus (Fig. $5 C, D$ ). Furthermore, as measured by immunoblotting, neither PHF1 levels $\left(F_{(5,8)}=1.78, p=0.47\right)$ nor total tau levels $\left(F_{(2,8)}=4.31, p=0.17\right)$ were altered by CORT administration (Fig. $5 E$ ). In addition, chronic direct administration of the synthetic glucocorticoid dexamethasone $(5 \mathrm{mg} / \mathrm{kg})$ also had no effect on tau hyperphosphorylation, as measured by PHF1 Western blot analysis (data not shown). Together, these data suggest that CORT is not the crucial stress hormone mediating the stress-induced changes in tau hyperphosphorylation observed in this study. Although this finding is surprising in light of previous literature supporting the glucocorticoid hypothesis of brain aging, it is consistent with emerging evidence that CORT does not mediate stress-induced changes in either $A \beta$ (Kang et al., 2007) or ptau (Rissman et al., 2007).

Experiment 4: $\mathrm{CRF}_{1}$ mediates stress-induced tau pathological inclusions, neurodegeneration, and fear-associated learning Based on our results suggesting that the mechanism behind stress-induced increases in ptau may be CORT-independent and previous studies suggesting involvement of CRF (Kang et al., 2007; Rissman et al., 2007), we sought to determine the role of $\mathrm{CRF}_{1}$ in stress-induced tau phosphorylation. Therefore, the selective $\mathrm{CRF}_{1}$ antagonist NBI 27914 was administered before stress in an effort to block tau phosphorylation. PS19 mice were evaluated after 1 month treatment with NS, 3 h/d of RI stress, or RI 
stress after treatment with NBI, as depicted in Figure $6 \mathrm{~A}$. Examination of brain and plasma drug concentrations after subcutaneous injections of $10 \mathrm{mg} / \mathrm{kg}$ NBI revealed that effective concentrations of the drug reached the brain at levels that exceeded the reported binding constant to the $\mathrm{CRF}_{1}$ receptor for several hours (Fig. $6 B)$. This dose demonstrated high drug levels in brain and a high but transient plasma drug level that was cleared within $2-4 \mathrm{~h}$. After chronic administration, the NBI and vehicle treatment groups did not display significant differences in body weight $\left(F_{(2,23)}=2.78, p=0.08\right)$, suggesting that the drug was well tolerated. Furthermore, the experimental animals receiving 1 month of chronic NBI treatment displayed high brain NBI levels $(66.2 \pm 9.5 \mathrm{nM})$ at the time of death, which was $3 \mathrm{~d}$ after the last injection. This suggests that relatively high brain concentrations of NBI were maintained throughout the study period. Consistent with our result in Figure 3, vehicle-treated RI mice displayed significantly more neurofibrillary tangle-like inclusions and higher AT8-IR levels in the hippocampus compared with NS mice (Fig. 6C), as quantified in Figure 6D. Furthermore, vehicle-treated RI mice displayed both significantly higher soluble and insoluble PHF1 levels when normalized to total tau (17025 antibody), although total tau levels were unchanged when normalized to $\operatorname{GAPDH}\left(F_{(3,10)}=12.9, p=0.3\right)$ (Fig. 6E). Last, consistent with our results in Figure 3, RI stress significantly impaired both contextual and cued fear-associated memory (Fig. 6F). Importantly, the pre-stress injection of a $\mathrm{CRF}_{1}$ antagonist NBI significantly prevented the stress-induced impairment in fear-associated memory, AT8-IR tau inclusions, and ptau $(p<0.05)$. These effects of NBI suggest that CRF acting at $\mathrm{CRF}_{1}$ is a crucial mediator of the stress-induced exacerbation of $\mathrm{AD}$-related ptau that leads to impairment of fear conditioning.

To evaluate the involvement of $\mathrm{CRF}_{1}$ in mediating neurodegeneration, we completed a semiquantitative analysis of hippocampal degeneration by NeuN immunohistochemistry and also measured hemi-hippocampal weight. Similar to our results in Figure 3, we observed that RI induced cell loss in the hippocampus (Fig. 6G) and hemi-hippocampal weight (Fig. $6 \mathrm{H}$ ) compared with NS mice, whereas NBI treatment significantly prevented this loss. Together, these results suggest that $\mathrm{CRF}_{1}$ is the primary mediator of stress-induced neurodegeneration in PS19 mice.

Last, to further confirm our hypothesis that CRF is integrally involved in stress-mediated elevation of tau phosphorylation, we used CRF-OE mice that have a chronic overproduction of CRF driven by the murine metallothionine 1 promoter and that display Cushing's disease-like features, as well as increased anxiety and stress sensitivity (Stenzel-Poore et al., 1992). The levels of phosphorylated PHF1 tau were quantified in the hippocampus of 10month-old CRF-OE mice and littermate controls, and we observed a substantial elevation in PHF1 levels in CRF-OE mice compared with WT littermates without a significant change in total tau levels (assessed with Tau 1 and T49 antibodies) when normalized to
D
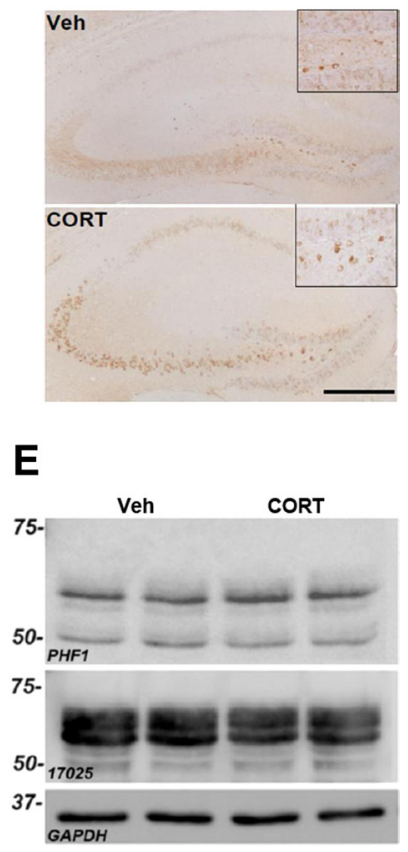

Figure 5. CORT treatment does not mimic chronic stress-induced tau hyperphosphorylation in PS19 mice. $A$, Experimental

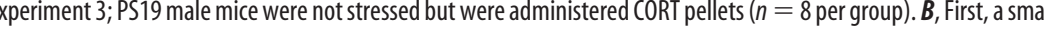
a hieved by these pellets. A high spike in CORT within the first $72 \mathrm{~h}$ was significantly higher $\left(F_{(2.7)}=2.25, p<0.0001\right)$ than after (O) nor R quantification using a semiquantitative rating scale (0-5) (D) showed a treatment difference. AU, Arbiry units; Veh, vehicle. Data show mean \pm SEM AT8 score. $E$, A representative Western blot probed for both PHF1, 17025, and GAPDH as a loading control also demonstrate no difference after CORT treatment in the hippocampus. Scale bar, $0.5 \mathrm{~mm}$.

$\operatorname{GAPDH}\left(F_{(2,4)}=4.39, p=0.5\right)$ (Fig. 6I). Although these mice do show altered CORT levels (Stenzel-Poore et al., 1992), our data above suggest that stress-induced changes in tau phosphorylation is CORT independent but CRF dependent. Together, these results suggest that enhanced CRF signaling is likely responsible for stressinduced exacerbation of tau phosphorylation.

\section{Discussion}

We sought to apply a paradigm of chronic stress, capable of exacerbating $\mathrm{A} \beta$ accumulation in the Tg2576 mouse model of $\mathrm{A} \beta$ plaque pathology, to a tau Tg mouse model to investigate the interaction between stress and disease-relevant tau pathology. Our data demonstrate that chronic RI stress worsens memory in both Tg2576 and PS19 mice, exacerbates A $\beta$ accumulation and suppresses microglial activation in the Tg2576 mice, and increases tau phosphorylation, neurodegeneration, and AT8-IR tau inclusions in the PS19 mice. Furthermore, both A $\beta$ and tau pathology alter the HPA profile. Importantly, CORT administration did not mimic the stress-induced promotion of tau pathology. However, $\mathrm{CRF}_{1}$ antagonism blocked tau pathology development, neurodegeneration, and learning impairments, whereas CRF-OE enhanced this effect, thereby implicating CRF signaling in mediating stress-induced tau pathology. These results represent a very comprehensive description of stress-induced changes in both $\mathrm{A} \beta$ and tau pathology in vivo and also implicate microglia for the first time in stress-induced augmentation of $A \beta$ levels. This is the first report of chronic stress-induced changes in pathological tau hyperphosphorylation and tau inclusions in a mouse that overexpresses a diseaserelevant tau mutation. 
A

Experiment 4: PS19 M

Age at Day 1: 7.0mo

Day

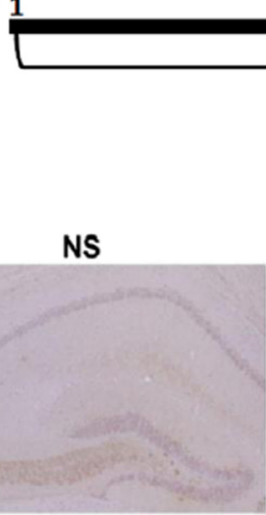

C

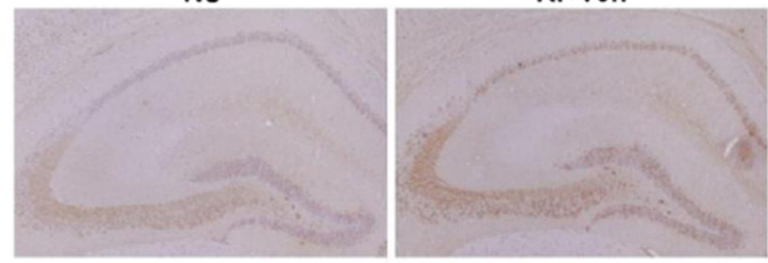

E

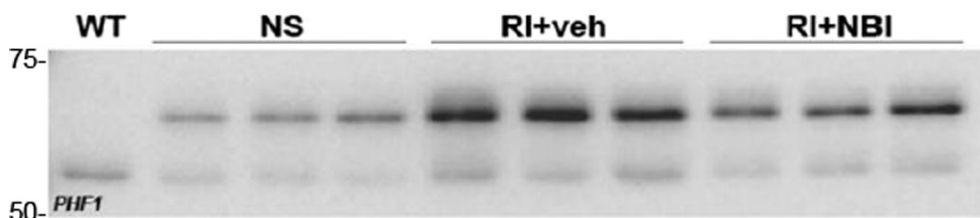

$75-$

50 -

50- 17025
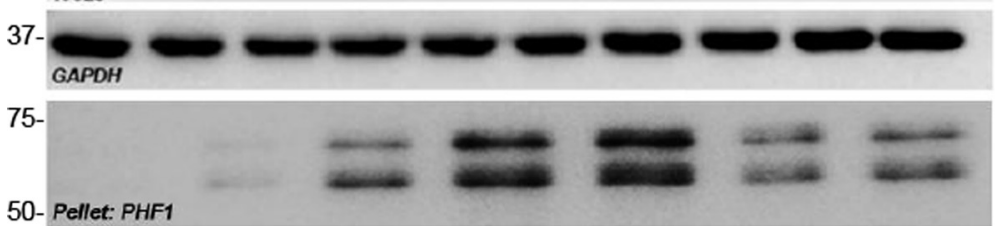

G

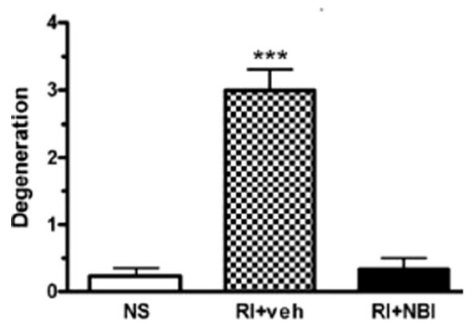

H

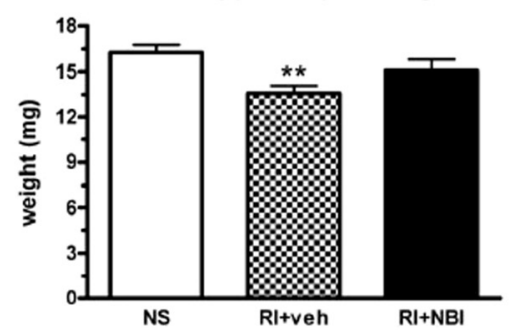

B
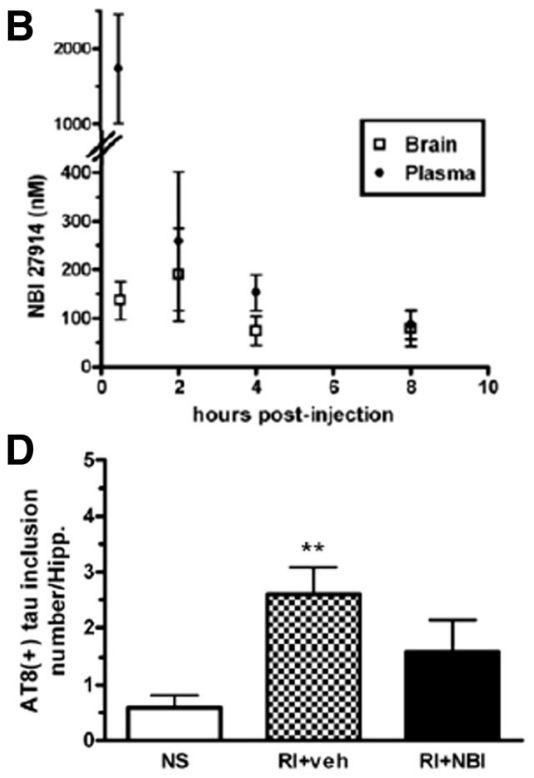
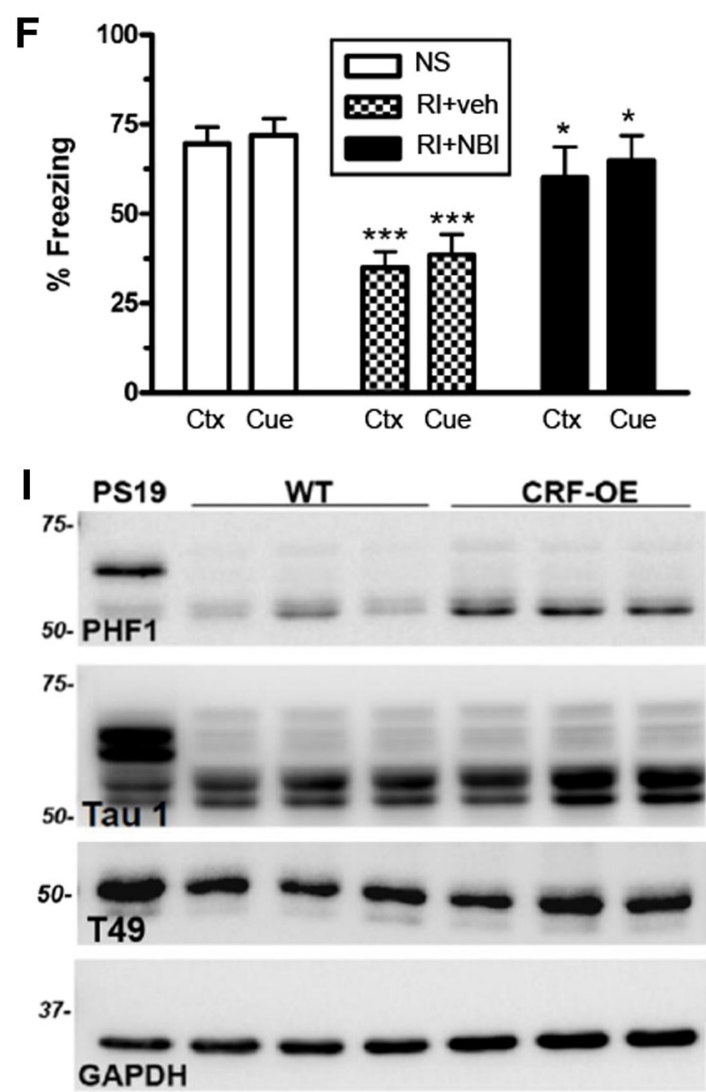

Figure 6. $\quad \mathrm{CRF}_{1}$ mediates stress-induced pathological tau inclusions, neurodegeneration, and fear-associated learning. $\boldsymbol{A}$, Experimental design of experiment 4 ; male PS19 mice were exposed to NS or Rl stress with pre-stress $\mathrm{CRF}_{1}$ antagonist (NBI) or vehicle subcutaneous injections ( $n=8$ per group). $B$, A small pilot study using adult WT female mice ( $n=3$ per group) was conducted to measure brain and plasma levels of NBI after a $10 \mathrm{mg} / \mathrm{kg}$ subcutaneous injection. C, Representative pictomicrographs demonstrate that vehicle-treated RI mice displayed significantly higher AT8-IR tau inclusions in the hippocampus, quantified in $\boldsymbol{D}\left(F_{(2,25)}=7.15, p=0.05\right)$, as well as soluble and insoluble PHF1, but not 17025 levels by Western blot $(\boldsymbol{E})$ that was blocked by a pre-stress injection of NBI. $\boldsymbol{F}$, Vehicle-treated RI mice also displayed fear-related learning impairments in both context ( $(\mathrm{tx})\left(F_{(2,28)}=12.4, p<0.05\right)$ and cued (Cue) $\left(F_{(2,28)}=9.3, p<0.05\right)$ fear conditioning that was significantly prevented by NBI. Data show mean \pm SEM percentage freezing. $G$, Compared with NS, vehicle-treated mice had significantly lower hippocampal weight $\left(F_{(2,44)}=6.44, p=0.004\right)$ and significantly increased NeuN ${ }^{+}-$IR degeneration scores $\left(F_{(2,28)}=6.19, p<0.001\right)(\boldsymbol{H})$, whereas NBI treatment significantly prevented both effects. I, Last, phosphorylated tau was quantified in the hippocampus of 10-month-old CRF-0E mice and WT littermate controls. A substantial elevation was observed in PHF1 levels in CRF-OE compared with WT littermates without a change in Tau 1 and T49 level. Data show mean \pm SEM PHF1 score. Scale bar, $0.5 \mathrm{~mm} .{ }^{* *} p<0.01,{ }^{* * *} p<0.001$ from NS. ${ }^{*} p<0.05$ from RI + vehicle. 
That chronic stress induces $\mathrm{A} \beta$ accumulation has been well established in a large body of research. Our results are consistent with these analogous findings after similar paradigms of restraint and/or isolation in $\mathrm{APP}_{\mathrm{V} 717 \mathrm{I}}-\mathrm{CT} 100$ (Jeong et al., 2006), Tg2576 (Lee et al., 2009), APPxPS1 (Huang et al., 2011), and 5XFAD mice (Devi et al., 2010). Also, stress increased $A \beta$ in brain interstitial fluid, possibly through a $\mathrm{CRF}_{1}$ but not CORT-dependent mechanism (Kang et al., 2007). However, our report and that by others of CORT independence are inconsistent with GR-dependent effects in 3xTg-AD mice (Green et al., 2006). This discrepancy may be dependent on the different mouse models (Tg2576 and PS19 vs $3 \times$ Tg-AD), different methods of ptau evaluation, different hormones (natural vs synthetic), and modes of delivery (intraperitoneal injections vs hormone pellets). However, it is possible that glucocorticoids still play an important role in this process. Corticosterone has been shown to exacerbate kainate-induced hippocampal ptau, neuron loss, and cytoskeletal pathology in vivo (Elliott et al., 1993; Stein-Behrens et al., 1994). It would be informative to investigate the AD-related pathological consequences of excess glucocorticoid production in patients with endocrine disorders such as Cushing's disease (Guldiken and Guldiken, 2008) to further understand the relationship between glucocorticoids and $\mathrm{AD}$.

Most importantly, our data strengthen the emerging hypothesis that stress induces tau pathology through a $\mathrm{CRF}_{1}$-dependent but CORT-independent mechanism (Dong and Csernansky, 2009). Our results suggest that stress-induced pathologic tau inclusion development, insoluble tau levels, neurodegeneration, and learning impairments are mediated by $\mathrm{CRF}_{1}$. Our findings also build on those from Sawchenko's group that stress increases endogenous mouse tau phosphorylation in WT mice, possibly through $\mathrm{CRF}_{1}$ (Rissman et al., 2007). However, others have demonstrated that CRF offers neuroprotective effects that are relevant to $\mathrm{AD}$ (for review, see Bayatti and Behl, 2005). In particular, known CRF receptor agonists were shown to be protective against cell death induced by $\mathrm{A} \beta$, lipid peroxidation, or excitotoxic glutamate in primary neuronal culture (Pedersen et al., 2001, 2002). However, these seemingly inconsistent results were obtained in vitro and represent a very different environment than a long-term, chronic stress paradigm in vivo. Acute and chronic stress and/or CRF exposure may have different effects on tau phosphorylation. Interestingly, we found that a single exposure to acute stress (15 min restraint) decreased tau phosphorylation in PS19 mice as assessed by AT8-IR immunohistochemistry and PHF1 biochemistry (J.C.C. and J.Q.T., unpublished observations), supporting the differential effects of acute versus chronic stress on tau phosphorylation.

Based on the known downstream signaling cascades associated with $\mathrm{CRF}_{1}$, several downstream targets may potentially link $\mathrm{CRF}$ to tau hyperphosphorylation. Agonist binding to $\mathrm{CRF}_{1}$ initiates the adenylyl cyclase-cAMP signaling pathway, PKAdependent protein phosphorylation, and CREB-dependent transcription regulation, as well as other signaling pathways, such as PKC, PKB/Akt, ERK, and p38 MAPK (Hauger et al., 2009). One important downstream target that has been directly linked to tau hyperphosphorylation is glycogen synthase kinase (GSK)$3 \beta$, a major protein kinase thought to be responsible for phosphorylating tau on various disease-specific sites (Avila et al., 2010). In cultured neurons, $\mathrm{CRF}_{1}$ activation initiates CREB signaling, which leads to phosphorylation of GSK3 $\beta$ (Bayatti et al., 2003; Facci et al., 2003). Recently, this link has also been reported in vivo, because stress induces GSK3 $\beta$ activation through phosphorylation at Tyr216 and increases ptau in wild-type mice (Riss- man et al., 2007). Nonetheless, other tau kinases, such as Fyn and Lck of the Src-kinase family (Scales et al., 2011), as well as various phosphatases, such as protein phosphatase 2B (Qian et al., 2011), are also interesting candidates that may be linked to $\mathrm{CRF}_{1}$ signaling and are planned targets of investigation by our laboratory. These studies will guide future efforts by which the kinases or signaling molecules can be pharmacologically manipulated in an effort to attenuate stress-induced tau phosphorylation.

Our data also suggest the possibility that stress alters microglial activation and perhaps the ability of these cells to clear $A \beta$ accumulation by phagocytosis. The link between $\mathrm{AD}, \mathrm{A} \beta$, and activation of the brain immune response, with the release of proinflammatory cytokines and chemokines, is well documented (Benzing et al., 1999; Farfara et al., 2008). Our findings are also consistent with known stress-induced disruption of neuron-microglia crosstalk (Biber et al., 2007), which can lead to an aberrant brain immune response (Jurgens and Johnson, 2010). Both aging and stress can induce deleterious microglia morphology and physiology alterations (Neumann, 2001; Pocock and Kettenmann, 2007). Furthermore, aged and diseased brains are more sensitive to stress effects and seem unable to adapt to the continued presence of a stressor (Buchanan et al., 2008). Although these conditions are usually associated with excessive microglia activation, it is also possible that aging, disease, and/or stress may suppress microglia activation depending on concentration, timing, and duration (acute vs chronic) of the stressor (Glezer and Rivest, 2004; Sorrells and Sapolsky, 2007; Dhabhar, 2009), a phenomenon that has been described in human brains (De la Fuente and Gimenez-Llort, 2010). Future studies designed to measure levels of cytokines, such as interleukin IL- $1 \beta$, IL- 6 , and tumor necrosis factor- $\alpha$, as well as M1 and M2 macrophage markers, would help clarify these issues.

One very interesting observation from this study was the differential effects of various stressors. Although RI had detrimental effects on spatial and fear memory, $A \beta$, and tau, VS only impaired fear memory, presumably through an $\mathrm{A} \beta$-independent mechanism or a process that occurs before overt $\mathrm{A} \beta$ deposition, such as synaptic plasticity dysfunction. Although both paradigms succeeded in invoking stress, they differed greatly in the amount of required physical activity. VS stress induced higher physical activity, either directly or indirectly, in the majority of its six stressors, whereas RI stress by definition reduced physical activity. It is possible that the VS induced an increase in exercise or environmental enrichment, both of which have consistently been shown to reduce indices of neuropathology in $\mathrm{Tg}$ mice (Nithianantharajah and Hannan, 2006; Radak et al., 2010). The differential effects of both stressors are also consistent with the hypothesis that the brain categorizes stressors and signals category-specific responses (Li et al., 1996; Herman and Cullinan, 1997; Sawchenko et al., 2000; Dayas et al., 2001). Although the differential pathways are not completely understood, this observation raises interesting questions regarding the different molecular mechanisms that link stress-induced AD risk in patients with psychological, emotional, or physical stress.

One limitation of this study is gender variation. Female Tg2576 and male PS19 mice were chosen for their higher and more consistent $\mathrm{A} \beta$ (Callahan et al., 2001) and tau pathology burden, respectively (Y. Yoshiyama and V.M.Y.L., unpublished observations). However, it has been well documented that gender differences exist in several important stress-sensitive indices of hippocampal plasticity, such as dendrite remodeling, neurogenesis, and synapse formation (McEwen, 2002). It is possible that the two stress paradigms used in this study could have different 
effects on AD-related neuropathology in different genders. Although such investigation is beyond the scope of this study, appreciating gender differences in stress-induced AD-related pathology is important to understanding the link between stress, gender, and risk for neurodegenerative disorders.

Finally, these data raise an interesting link between $\mathrm{AD}$, stressrelated psychiatric disorders, endocrine disorders, and gender. Both AD and several stress disorders are characterized by HPA dysfunction (Swaab et al., 2005; Holsboer and Ising, 2008; Pervanidou and Chrousos, 2010). Increased CRF release or function has been implicated in many stress-related psychiatric disorders, such as depression (Gold and Chrousos, 2002). Furthermore, neither risk for stress-related psychiatric disorders nor neurodegenerative diseases is gender neutral (Bachman et al., 1992; Ruitenberg et al., 2001; Cahill, 2006; Figueira and Ouakinin, 2010). Therefore, it is possible that stress differentially influences disease risk depending on gender. In this light, given the emerging potential role of CRF in $\mathrm{A} \beta$ aggregation and tau pathology, increased CRF in stress-related psychiatric disorders would be predicted to predispose to $\mathrm{AD}$. Understanding this emerging link between CRF, AD-related pathology, and stress is of crucial importance in future treatments of not only neurodegenerative diseases but also psychiatric disorders.

\section{References}

Alfarez DN, Joëls M, Krugers HJ (2003) Chronic unpredictable stress impairs long-term potentiation in rat hippocampal CA1 area and dentate gyrus in vitro. Eur J Neurosci 17:1928-1934.

Arendt T, Stieler J, Strijkstra AM, Hut RA, Rüdiger J, Van der Zee EA, Harkany T, Holzer M, Härtig W (2003) Reversible paired helical filamentlike phosphorylation of tau is an adaptive process associated with neuronal plasticity in hibernating animals. J Neurosci 23:6972-6981.

Avila J, Wandosell F, Hernández F (2010) Role of glycogen synthase kinase-3 in Alzheimer's disease pathogenesis and glycogen synthase kinase-3 inhibitors. Expert Rev Neurother 10:703-710.

Aznar S, Knudsen GM (2011) Depression and Alzheimer's disease: is stress the initiating factor in a common neuropathological cascade? J Alzheimers Dis 23:177-193.

Bachman DL, Wolf PA, Linn R, Knoefel JE, Cobb J, Belanger A, D’Agostino RB, White LR (1992) Prevalence of dementia and probable senile dementia of the Alzheimer type in the Framingham Study. Neurology 42:115-119.

Bale TL, Vale WW (2004) CRF and CRF receptors: role in stress responsivity and other behaviors. Annu Rev Pharmacol Toxicol 44:525-557.

Bao AM, Meynen G, Swaab DF (2008) The stress system in depression and neurodegeneration: focus on the human hypothalamus. Brain Res Rev 57:531-553.

Bayatti N, Behl C (2005) The neuroprotective actions of CRH. Ageing Res Rev 4:258-270.

Bayatti N, Zschocke J, Behl C (2003) Brain region-specific neuroprotective action and signaling of corticotropin-releasing hormone in primary neurons. Endocrinology 144:4051-4060.

Benzing WC, Wujek JR, Ward EK, Shaffer D, Ashe KH, Younkin SG, Brunden KR (1999) Evidence for glial-mediated inflammation in aged APP(SW) transgenic mice. Neurobiol Aging 20:581-589.

Biber K, Neumann H, Inoue K, Boddeke HW (2007) Neuronal "On” and "Off" signals control microglia. Trends Neurosci 30:596-602.

Brunden KR, Zhang B, Carroll J, Yao Y, Potuzak JS, Hogan AM, Iba M, James MJ, Xie SX, Ballatore C, Smith AB 3rd, Lee VM, Trojanowski JQ (2010) Epothilone D improves microtubule density, axonal integrity, and cognition in a transgenic mouse model of tauopathy. J Neurosci 30:13861-13866.

Brunden KR, Yao Y, Potuzak JS, Ferrer NI, Ballatore C, James MJ, Hogan AM, Trojanowski JQ, Smith AB 3rd, Lee VM (2011) The characterization of microtubule-stabilizing drugs as possible therapeutic agents for Alzheimer's disease and related tauopathies. Pharmacol Res 63:341-351.

Buchanan JB, Sparkman NL, Chen J, Johnson RW (2008) Cognitive and neuroinflammatory consequences of mild repeated stress are exacerbated in aged mice. Psychoneuroendocrinology 33:755-765.
Cahill L (2006) Why sex matters for neuroscience. Nat Rev Neurosci $7: 477-484$

Callahan MJ, Lipinski WJ, Bian F, Durham RA, Pack A, Walker LC (2001) Augmented senile plaque load in aged female beta-amyloid precursor protein-transgenic mice. Am J Pathol 158:1173-1177.

Carroll JC, Pike CJ (2008) Selective estrogen receptor modulators differentially regulate Alzheimer-like changes in female 3xTg-AD mice. Endocrinology 149:2607-2611.

Carroll JC, Rosario ER, Chang L, Stanczyk FZ, Oddo S, LaFerla FM, Pike CJ (2007) Progesterone and estrogen regulate Alzheimer-like neuropathology in female 3xTg-AD mice. J Neurosci 27:13357-13365.

Carroll JC, Rosario ER, Villamagna A, Pike CJ (2010) Continuous and cyclic progesterone differentially interact with estradiol in the regulation of Alzheimer-like pathology in female 3xTransgenic-Alzheimer's disease mice. Endocrinology 151:2713-2722.

Csernansky JG, Dong H, Fagan AM, Wang L, Xiong C, Holtzman DM, Morris JC (2006) Plasma cortisol and progression of dementia in subjects with Alzheimer-type dementia. Am J Psychiatry 163:2164-2169.

Dayas CV, Buller KM, Crane JW, Xu Y, Day TA (2001) Stressor categorization: acute physical and psychological stressors elicit distinctive recruitment patterns in the amygdala and in medullary noradrenergic cell groups. Eur J Neurosci 14:1143-1152.

De la Fuente M, Gimenez-Llort L (2010) Models of aging of neuroimmunomodulation: strategies for its improvement. Neuroimmunomodulation 17:213-216.

Devi L, Alldred MJ, Ginsberg SD, Ohno M (2010) Sex- and brain regionspecific acceleration of beta-amyloidogenesis following behavioral stress in a mouse model of Alzheimer's disease. Mol Brain 3:34.

Dhabhar FS (2009) Enhancing versus suppressive effects of stress on immune function: implications for immunoprotection and immunopathology. Neuroimmunomodulation 16:300-317.

Dong H, Csernansky JG (2009) Effects of stress and stress hormones on amyloid-beta protein and plaque deposition. J Alzheimers Dis $18: 459-469$.

Elliott EM, Mattson MP, Vanderklish P, Lynch G, Chang I, Sapolsky RM (1993) Corticosterone exacerbates kainate-induced alterations in hippocampal tau immunoreactivity and spectrin proteolysis in vivo. J Neurochem 61:57-67.

Facci L, Stevens DA, Pangallo M, Franceschini D, Skaper SD, Strijbos PJ (2003) Corticotropin-releasing factor (CRF) and related peptides confer neuroprotection via type 1 CRF receptors. Neuropharmacology 45:623-636.

Farfara D, Lifshitz V, Frenkel D (2008) Neuroprotective and neurotoxic properties of glial cells in the pathogenesis of Alzheimer's disease. J Cell Mol Med 12:762-780.

Feng Q, Cheng B, Yang R, Sun FY, Zhu CQ (2005) Dynamic changes of phosphorylated tau in mouse hippocampus after cold water stress. Neurosci Lett 388:13-16.

Figueira ML, Ouakinin S (2010) Gender-related endocrinological dysfunction and mental disorders. Curr Opin Psychiatry 23:369-372.

Glezer I, Rivest S (2004) Glucocorticoids: protectors of the brain during innate immune responses. Neuroscientist 10:538-552.

Gold PW, Chrousos GP (2002) Organization of the stress system and its dysregulation in melancholic and atypical depression: high vs low CRH/NE states. Mol Psychiatry 7:254-275.

Green KN, Billings LM, Roozendaal B, McGaugh JL, LaFerla FM (2006) Glucocorticoids increase amyloid- $\beta$ and tau pathology in a mouse model of Alzheimer's disease. J Neurosci 26:9047-9056.

Guldiken S, Guldiken B (2008) Subclinical Cushing's syndrome is a potential cause of metabolic dementia and rapidly progressive Alzheimer-type dementia. Med Hypotheses 71:703-705.

Hauger RL, Risbrough V, Oakley RH, Olivares-Reyes JA, Dautzenberg FM (2009) Role of CRF receptor signaling in stress vulnerability, anxiety, and depression. Ann N Y Acad Sci 1179:120-143.

Herman JP, Cullinan WE (1997) Neurocircuitry of stress: central control of the hypothalamo-pituitary-adrenocortical axis. Trends Neurosci 20:78-84.

Herrmann M, Henneicke H, Street J, Modzelewski J, Kalak R, Buttgereit F, Dunstan CR, Zhou H, Seibel MJ (2009) The challenge of continuous exogenous glucocorticoid administration in mice. Steroids 74:245-249.

Hillhouse EW, Grammatopoulos DK (2006) The molecular mechanisms underlying the regulation of the biological activity of corticotropin- 
releasing hormone receptors: implications for physiology and pathophysiology. Endocr Rev 27:260-286.

Hoare SR, Sullivan SK, Schwarz DA, Ling N, Vale WW, Crowe PD, Grigoriadis DE (2004) Ligand affinity for amino-terminal and juxtamembrane domains of the corticotropin releasing factor type I receptor: regulation by G-protein and nonpeptide antagonists. Biochemistry 43:3996-4011.

Holsboer F, Ising M (2008) Central CRH system in depression and anxietyevidence from clinical studies with CRH1 receptor antagonists. Eur J Pharmacol 583:350-357.

Huang HJ, Liang KC, Ke HC, Chang YY, Hsieh-Li HM (2011) Long-term social isolation exacerbates the impairment of spatial working memory in APP/PS1 transgenic mice. Brain Res 1371:150-160.

Hurtado DE, Molina-Porcel L, Iba M, Aboagye AK, Paul SM, Trojanowski JQ, Lee VM (2010) A $\beta$ accelerates the spatiotemporal progression of tau pathology and augments tau amyloidosis in an Alzheimer mouse model. Am J Pathol 177:1977-1988.

Jeong YH, Park CH, Yoo J, Shin KY, Ahn SM, Kim HS, Lee SH, Emson PC, Suh YH (2006) Chronic stress accelerates learning and memory impairments and increases amyloid deposition in APPV717I-CT100 transgenic mice, an Alzheimer's disease model. FASEB J 20:729-731.

Jurgens HA, Johnson RW (2010) Dysregulated neuronal-microglial cross-talk during aging, stress and inflammation. Exp Neurol. Advance online publication. Retrieved August 29, 2011. doi:10.1016/j.expneurol.2010.11.014.

Kang JE, Cirrito JR, Dong H, Csernansky JG, Holtzman DM (2007) Acute stress increases interstitial fluid amyloid-beta via corticotropin-releasing factor and neuronal activity. Proc Natl Acad Sci USA 104:10673-10678.

Kim JJ, Diamond DM (2002) The stressed hippocampus, synaptic plasticity and lost memories. Nat Rev Neurosci 3:453-462.

Korneyev A, Binder L, Bernardis J (1995) Rapid reversible phosphorylation of rat brain tau proteins in response to cold water stress. Neurosci Lett 191:19-22.

Landfield PW, Blalock EM, Chen KC, Porter NM (2007) A new glucocorticoid hypothesis of brain aging: implications for Alzheimer's disease. Curr Alzheimer Res 4:205-212.

Lee BK, Glass TA, Wand GS, McAtee MJ, Bandeen-Roche K, Bolla KI, Schwartz BS (2008) Apolipoprotein e genotype, cortisol, and cognitive function in community-dwelling older adults. Am J Psychiatry 165:1456-1464.

Lee EB, Skovronsky DM, Abtahian F, Doms RW, Lee VM (2003) Secretion and intracellular generation of truncated Abeta in beta-site amyloid-beta precursor protein-cleaving enzyme expressing human neurons. J Biol Chem 278:4458-4466.

Lee KW, Kim JB, Seo JS, Kim TK, Im JY, Baek IS, Kim KS, Lee JK, Han PL (2009) Behavioral stress accelerates plaque pathogenesis in the brain of Tg2576 mice via generation of metabolic oxidative stress. J Neurochem 108:165-175.

Li HY, Ericsson A, Sawchenko PE (1996) Distinct mechanisms underlie activation of hypothalamic neurosecretory neurons and their medullary catecholaminergic afferents in categorically different stress paradigms. Proc Natl Acad Sci USA 93:2359-2364.

Luo Y, Bolon B, Kahn S, Bennett BD, Babu-Khan S, Denis P, Fan W, Kha H, Zhang J, Gong Y, Martin L, Louis JC, Yan Q, Richards WG, Citron M, Vassar R (2001) Mice deficient in BACE1, the Alzheimer's betasecretase, have normal phenotype and abolished beta-amyloid generation. Nat Neurosci 4:231-232.

Magariños AM, McEwen BS (1995) Stress-induced atrophy of apical dendrites of hippocampal CA3c neurons: comparison of stressors. Neuroscience 69:83-88.

McEwen BS (1999) Stress and hippocampal plasticity. Annu Rev Neurosci 22:105-122.

McEwen BS (2002) Sex, stress and the hippocampus: allostasis, allostatic load and the aging process. Neurobiol Aging 23:921-939.

Nakagawa Y, Nakamura M, McIntosh TK, Rodriguez A, Berlin JA, Smith DH, Saatman KE, Raghupathi R, Clemens J, Saido TC, Schmidt ML, Lee VM, Trojanowski JQ (1999) Traumatic brain injury in young, amyloid-beta peptide overexpressing transgenic mice induces marked ipsilateral hippocampal atrophy and diminished Abeta deposition during aging. J Comp Neurol 411:390-398.

Neumann H (2001) Control of glial immune function by neurons. Glia 36:191-199.

Nithianantharajah J, Hannan AJ (2006) Enriched environments, experience- dependent plasticity and disorders of the nervous system. Nat Rev Neurosci 7:697-709.

Papasozomenos SC (1996) Heat shock induces rapid dephosphorylation of tau in both female and male rats followed by hyperphosphorylation only in female rats: implications for Alzheimer's disease. J Neurochem 66:1140-1149.

Patil SS, Sunyer B, Höger H, Lubec G (2009) Evaluation of spatial memory of C57BL/6J and CD1 mice in the Barnes maze, the Multiple T-maze and in the Morris water maze. Behav Brain Res 198:58-68.

Pedersen WA, McCullers D, Culmsee C, Haughey NJ, Herman JP, Mattson MP (2001) Corticotropin-releasing hormone protects neurons against insults relevant to the pathogenesis of Alzheimer's disease. Neurobiol Dis 8:492-503.

Pedersen WA, Wan R, Zhang P, Mattson MP (2002) Urocortin, but not urocortin II, protects cultured hippocampal neurons from oxidative and excitotoxic cell death via corticotropin-releasing hormone receptor type I. J Neurosci 22:404-412.

Pervanidou P, Chrousos GP (2010) Neuroendocrinology of post-traumatic stress disorder. Prog Brain Res 182:149-160.

Planel E, Yasutake K, Fujita SC, Ishiguro K (2001) Inhibition of protein phosphatase $2 \mathrm{~A}$ overrides tau protein kinase I/glycogen synthase kinase 3 beta and cyclin-dependent kinase 5 inhibition and results in tau hyperphosphorylation in the hippocampus of starved mouse. J Biol Chem 276:34298-34306.

Pocock JM, Kettenmann H (2007) Neurotransmitter receptors on microglia. Trends Neurosci 30:527-535.

Qian W, Yin X, Hu W, Shi J, Gu J, Grundke-Iqbal I, Iqbal K, Gong CX, Liu F (2011) Activation of protein phosphatase 2B and hyperphosphorylation of tau in Alzheimer's disease. J Alzheimers Dis 23:617-627.

Radak Z, Hart N, Sarga L, Koltai E, Atalay M, Ohno H, Boldogh I (2010) Exercise plays a preventive role against Alzheimer's disease. J Alzheimers Dis 20:777-783.

Rissman RA, Lee KF, Vale W, Sawchenko PE (2007) Corticotropinreleasing factor receptors differentially regulate stress-induced tau phosphorylation. J Neurosci 27:6552-6562.

Rothman SM, Mattson MP (2010) Adverse stress, hippocampal networks, and Alzheimer's disease. Neuromolecular Med 12:56-70.

Ruitenberg A, Ott A, van Swieten JC, Hofman A, Breteler MM (2001) Incidence of dementia: does gender make a difference? Neurobiol Aging 22:575-580.

Sapolsky RM, Krey LC, McEwen BS (1985) Prolonged glucocorticoid exposure reduces hippocampal neuron number: implications for aging. J Neurosci 5:1222-1227.

Sawchenko PE, Li HY, Ericsson A (2000) Circuits and mechanisms governing hypothalamic responses to stress: a tale of two paradigms. Prog Brain Res 122:61-78.

Scales TM, Derkinderen P, Leung KY, Byers HL, Ward MA, Price C, Bird IN, Perera T, Kellie S, Williamson R, Anderton BH, Reynolds CH (2011) Tyrosine phosphorylation of tau by the SRC family kinases lck and fyn. Mol Neurodegener 6:12.

Sorrells SF, Sapolsky RM (2007) An inflammatory review of glucocorticoid actions in the CNS. Brain Behav Immun 21:259-272.

Stein-Behrens B, Mattson MP, Chang I, Yeh M, Sapolsky R (1994) Stress exacerbates neuron loss and cytoskeletal pathology in the hippocampus. J Neurosci 14:5373-5380.

Stengel A, Taché Y (2010) Corticotropin-releasing factor signaling and visceral response to stress. Exp Biol Med (Maywood) 235:1168-1178.

Stenzel-Poore MP, Cameron VA, Vaughan J, Sawchenko PE, Vale W (1992) Development of Cushing's syndrome in corticotropin-releasing factor transgenic mice. Endocrinology 130:3378-3386.

Swaab DF, Bao AM, Lucassen PJ (2005) The stress system in the human brain in depression and neurodegeneration. Ageing Res Rev 4:141-194.

Teegarden SL, Bale TL (2008) Effects of stress on dietary preference and intake are dependent on access and stress sensitivity. Physiol Behav 93:713-723.

Watanabe Y, Gould E, McEwen BS (1992) Stress induces atrophy of apical dendrites of hippocampal CA3 pyramidal neurons. Brain Res 588:341-345.

Wellman CL, Izquierdo A, Garrett JE, Martin KP, Carroll J, Millstein R, Lesch 
KP, Murphy DL, Holmes A (2007) Impaired stress-coping and fear extinction and abnormal corticolimbic morphology in serotonin transporter knock-out mice. J Neurosci 27:684-691.

West MJ, Slomianka L, Gundersen HJ (1991) Unbiased stereological estimation of the total number of neurons in thesubdivisions of the rat hippocampus using the optical fractionator. Anat Rec 231:482-497.

Wilson RS, Arnold SE, Schneider JA, Kelly JF, Tang Y, Bennett DA (2006) Chronic psychological distress and risk of Alzheimer's disease in old age. Neuroepidemiology 27:143-153.

Yanagisawa M, Planel E, Ishiguro K, Fujita SC (1999) Starvation induces tau hyperphosphorylation in mouse brain: implications for Alzheimer's disease. FEBS Lett 461:329-333.
Yan J, Sun XB, Wang HQ, Zhao H, Zhao XY, Xu YX, Guo JC, Zhu CQ (2010) Chronic restraint stress alters the expression and distribution of phosphorylated tau and MAP2 in cortex and hippocampus of rat brain. Brain Res 1347:132-141.

Yoshiyama Y, Higuchi M, Zhang B, Huang SM, Iwata N, Saido TC, Maeda J, Suhara T, Trojanowski JQ, Lee VM (2007) Synapse loss and microglial activation precede tangles in a P301S tauopathy mouse model. Neuron 53:337-351

Zhang LF, Shi L, Liu H, Meng FT, Liu YJ, Wu HM, Du X, Zhou JN (2011) Increased hippocampal tau phosphorylation and axonal mitochondrial transport in a mouse model of chronic stress. Int J Neuropsychopharma$\operatorname{col} 22: 1-12$ 